\title{
Seismic Tremors and Their Relation to Cryosphere Dynamics in April 2015 around the Lützow-Holm Bay, East Antarctica
}

\author{
Masaki Kanao ${ }^{1 *}$, Takahiko Murayama², Masa-Yuki Yamamoto ${ }^{3}$, Yoshiaki Ishihara4 \\ ${ }^{1}$ National Institute of Polar Research, Research Organization of Information and Systems, Tokyo, Japan \\ ${ }^{2}$ Japan Weather Association, Tokyo, Japan \\ ${ }^{3}$ Kochi University of Technology, Kochi, Japan \\ ${ }^{4}$ Japan Aerospace Exploration Agency, Kanagawa, Japan \\ Email: *kanao@nipr.ac.jp,murayama@jwa.or.jp,yamamoto.masa-yuki@kochi-tech.ac.jp, ishihara.yoshiaki@jaxa.jp
}

How to cite this paper: Kanao, M., Murayama, T., Yamamoto, M.-Y. and Ishihara, Y. (2017) Seismic Tremors and Their Relation to Cryosphere Dynamics in April 2015 around the Lützow-Holm Bay, East Antarctica. International Journal of Geosciences, 8, 1025-1047.

https://doi.org/10.4236/ijg.2017.88058

Received: July 18, 2017

Accepted: August 26, 2017

Published: August 30, 2017

Copyright $\odot 2017$ by authors and Scientific Research Publishing Inc. This work is licensed under the Creative Commons Attribution International License (CC BY 4.0).

http://creativecommons.org/licenses/by/4.0/

\begin{abstract}
Characteristics and statistics of seismic tremors occurring during April 2015 were investigated by using short-period and broadband seismographs deployed at Syowa Station (SYO), in the Lützow-Holm Bay (LHB), East Antarctica. In order to examine a relationship between surface environments in particular cryosphere variation, the MODIS satellite images were utilized for comparison with the detected tremor events. Since a large volume of sea-ice was discharged during the April, together with several large icebergs passed through from the west to the east at northern edge of the fast sea-ice of LHB, it was expected to detect seismic tremors involving cryospehre dynamics. During the month, a total number of 49 tremor events including short duration ice shocks were identified. Majority of the events $(\mathrm{N}=39)$ had their duration times more than 15 minutes, which were divided into both tremors and ice shocks on the basis of experienced definition at SYO. Cryospheric sources recorded by seismic tremors were classified into several origins (collision, calving, crevassing, crashing, etc.): "crevassing events" along the large cracks inside the fast sea-ice in LHB (04 April), "discharge events" of fast sea-ice from the Bay (07 April), "collision events" between iceberg and the edge of fast sea-ice (14 April), "crashing movement" between fragmentation of fast sea-ice and packed sea-ice (18 April), and other origins. In particular, strong amplitude tremors with harmonic overtones were assumed to be occurred independently from whether condition, because these overtone tremors were identified at less stormy days by comparison with infrasound data at SYO.
\end{abstract}

\section{Keywords}

Seismic Tremors, Ice Shocks, Cryosphere Dynamics, Sea-Ice, Icebergs, 


\section{Introduction}

Several kinds of ice-relating seismic waves, here we say "cryoseismic" signals, have been studied in many local areas of Antarctica in last two decades before and after the International Polar Year (IPY2007-2008). During the IPY, the "Polar Earth Observing Network (POLENET)" was the largest contributions to establishing seismic and geodetic networks within the whole Antarctic continent as well as Greenland [1]. Ice-related seismic events with small magnitude have generally been called as "ice shocks" or "ice quakes" and can be generated by cryosphere relating dynamics. These cyoseismic sources can be classified into several kinds; that is, the movements of ice sheets, sea-ice, oceanic tide-cracks, oceanic gravity waves, collision of icebergs and the calving fronts of ice caps, etc. [2] [3] [4] [5] [6] [7] [8].

As well as in Antarctica, cryoseismic signals were reported in particular associated with calving events of large glaciers in the Arctic [9] [10] [11]. Moreover, it is found that recently tide-modulated ice flow variations enhanced the seismicity near a calving front of Bowdoin Glacier, Greenland [12]. Some of these cryoseismic events, on the contrary, have a possibility that they include usual earthquakes, such as local tectonic events associated with faulting systems in the upper crust, volcanic activities, and glacial isostatic rebound movement. However, these cryoseismic dynamics are considered strongly involving surface environmental changes and evolution, and their space-time variability provide a proxy for monitoring climate change in polar region.

Cryoseismic activities around Syowa Station (SYO; 69S, 39E), in the LützowHolm Bay (LHB), Eastern Dronning Maud Land, East Antarctica, have been studied in past two decades (Figure 1). Local seismicity including cryoseismic signals around SYO were determined along the coast and edges of fast sea-ice in LHB [13]. These cryoseismic sources were estimated as the calving of glaciers, sea-ice movements, collision between icebergs based on their hypocentral locations. Sea-ice involved dynamics in offshore of LHB had also been excited the cryoseismic harmonic tremors. A large volume of fast sea-ice discharged in 1997 winter, and was clearly recorded by the seismographs at SYO [14] as a few tens of hour durating tremors with non-linear harmonic overtones.

Recently found tremors around LHB for the period from October 2014 to March 2015 were demonstrated in terms of surface envieronment by cryosphere evolution. A clear relationship between sea-ice conditions and iceberg dynamics was identified by comparison with MODIS satellite images [15]. In addition, statistics of the number of these tremors was investigated by comparing meteorological data at SYO for the same six months' of duration from October 2014, so as to reveal details of occurrence mechanism of these seismic tremors [16]. A total 


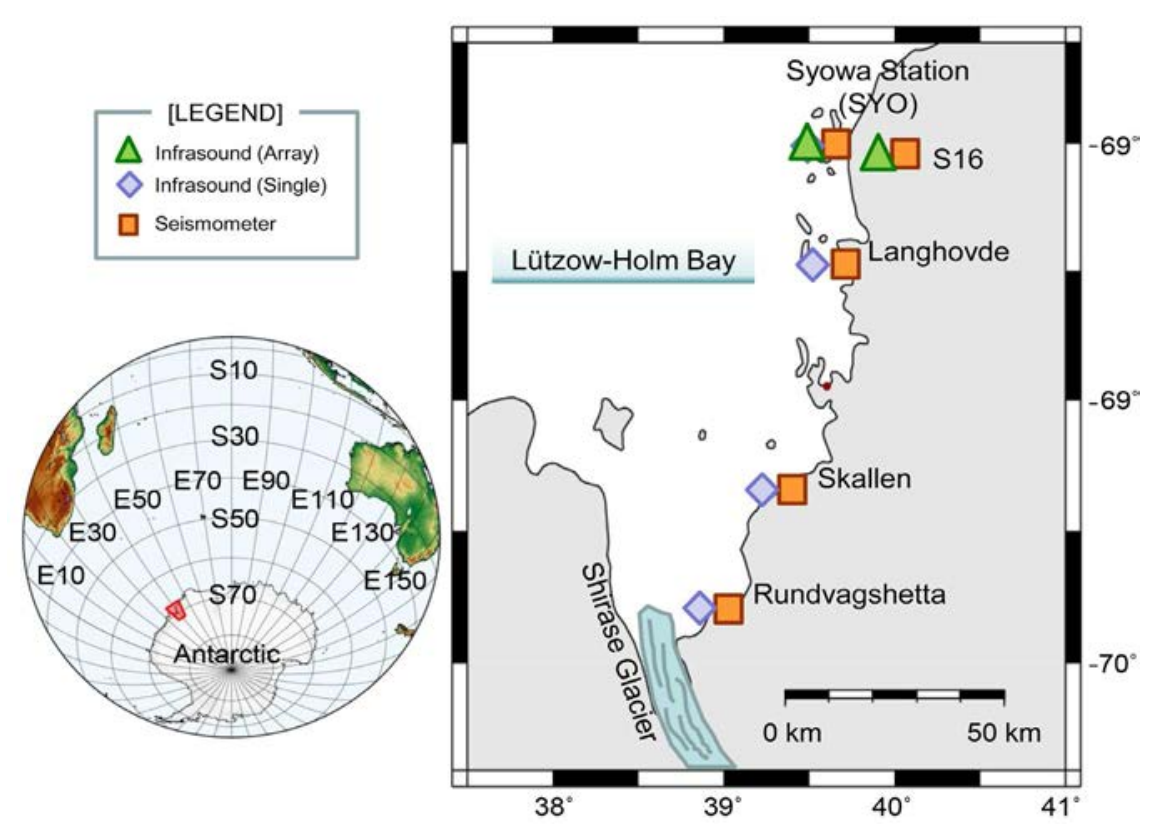

Figure 1. Distribution of seismic and infrasound stations around the Lützow-Holm Bay (LHB), East Antarctica. Three-component short-period and broadband seismographs have been operated at Syowa Station (SYO). Infrasound tripartite array stations have also been deployed at SYO in Ongul Islands and S16 site on the continental ice sheet. In addition, portable broadband seismographs and single infrasound sensors have been deployed at several sites along the coast of LHB.

number of 148 events including short-time duration ice shocks were identified. Statistics of the number of these tremors indicated that many of them occurred during the period of large increase in temperature and/or wind speed. In contrast, tremors of harmonic overtones with large amplitudes occurred independently from the other majority types of events (i.e, non-linear, small amplitude and weak signals), and had interpretation as the repetitive sources suggesting inter-glacial asperities such as collision of icebergs and fast sea-ice.

Following these previous studies in LHB, in this paper, characteristics and statistics of seismic tremors occurring during one month of April 2015 were especially studied by using seismographs deploying at SYO. To investigate a relationship between surface environments around the LHB in particular cryosphere dynamics, the MODIS satellite images were used for comparison with the seismic waveforms for each tremor events. Since a large volume of sea-ice was discharged during the month, moreover, several large icebergs had been passed in the northern edge of the Bay, it is expected to merge an interesting relationship between occurrence of seismic tremors and surrunding cryospehre environment.

\section{Seismic Tremors and Sea-Ice Environment}

During one month of April 2015, a total number of 49 tremor events including short duration ice shocks (ice quakes) were identified in both short-period (HES) and broadband seismographs (STS-1) at SYO (Table 1). Details of seismic 
Table 1. List of seismic tremors and ice shocks observed in April 2015.

\begin{tabular}{|c|c|c|c|c|c|c|}
\hline Date & From & To & Duration & Identified event & Amplitude & Rearks \\
\hline $2015 / 4 / 1$ & $2: 15$ & $2: 40$ & $0: 25$ & HT & small & $\mathrm{D}$ \\
\hline $2015 / 4 / 1$ & $23: 10$ & $23: 35$ & $0: 25$ & $\mathrm{HT}$ & small & $\mathrm{D}$ \\
\hline $2015 / 4 / 2$ & $12: 40$ & $12: 45$ & 0:05 & serge type & small & ice shock \\
\hline $2015 / 4 / 2$ & $12: 20$ & $12: 45$ & $0: 25$ & HT, serge type & small & $\mathrm{D}$ \\
\hline $2015 / 4 / 3$ & $0: 15$ & $0: 40$ & $0: 25$ & serge type & small & $\mathrm{D}$ \\
\hline $2015 / 4 / 4$ & $5: 10$ & $5: 25$ & $0: 15$ & serge type & small & ice shock, D \\
\hline $2015 / 4 / 4$ & $10: 30$ & $12: 00$ & $1: 30$ & HT, serge type & large & $\mathrm{D}$ \\
\hline $2015 / 4 / 5$ & $18: 35$ & $18: 40$ & $0: 05$ & serge type & small & \\
\hline $2015 / 4 / 5$ & $18: 25$ & $19: 35$ & $1: 10$ & HT, nonlinear & large & $\mathrm{D}$ \\
\hline $2015 / 4 / 6$ & $0: 40$ & $0: 50$ & $0: 10$ & serge type & small & ice shock \\
\hline $2015 / 4 / 6$ & $1: 10$ & $1: 15$ & 0:05 & serge type & small & ice shock \\
\hline $2015 / 4 / 6$ & $2: 40$ & $3: 00$ & $0: 20$ & serge type & small & $\mathrm{D}$ \\
\hline $2015 / 4 / 6$ & $7: 15$ & $7: 35$ & $0: 20$ & serge type & small & $\mathrm{D}$ \\
\hline $2015 / 4 / 6$ & $13: 40$ & $13: 50$ & $0: 10$ & serge type & small & $\mathrm{D}$ \\
\hline $2015 / 4 / 6$ & $15: 00$ & $15: 30$ & $0: 30$ & serge type & large & $\mathrm{D}$ \\
\hline $2015 / 4 / 7$ & $1: 00$ & $1: 15$ & $0: 15$ & serge type & small & ice shock \\
\hline $2015 / 4 / 7$ & $3: 10$ & $4: 30$ & $1: 20$ & serge type & large & ice shock \\
\hline $2015 / 4 / 7$ & $18: 50$ & $20: 05$ & $1: 15$ & serge type & small & ice shock \\
\hline $2015 / 4 / 8$ & $5: 20$ & $6: 20$ & $1: 00$ & nonlinear & small & $\mathrm{D}$ \\
\hline $2015 / 4 / 9$ & $21: 50$ & $22: 45$ & $0: 55$ & serge type & small & ice shocks \\
\hline $2015 / 4 / 10$ & 2:05 & $2: 40$ & $0: 35$ & serge type & small & ice shocks \\
\hline $2015 / 4 / 11$ & $1: 30$ & $4: 35$ & 3:05 & serge type & small & ice shocks \\
\hline $2015 / 4 / 12$ & $23: 10$ & $23: 15$ & 0:05 & serge type & small & ice shock \\
\hline $2015 / 4 / 13$ & $4: 50$ & $5: 10$ & $0: 20$ & serge type & small & ice shocks \\
\hline $2015 / 4 / 13$ & $5: 30$ & $5: 37$ & $0: 07$ & serge type & small & ice shock \\
\hline $2015 / 4 / 14$ & $16: 30$ & $17: 00$ & $0: 30$ & serge type & large & ice shock \\
\hline $2015 / 4 / 14$ & 19:00 & $0: 00$ & $5: 00$ & serge type & large & nonlinear, D \\
\hline $2015 / 4 / 15$ & $13: 45$ & $14: 45$ & $1: 00$ & serge type, nonlinear & small & ice shocks \\
\hline $2015 / 4 / 22$ & $2: 00$ & $2: 30$ & $0: 30$ & serge type & small & ice shock \\
\hline $2015 / 4 / 22$ & $11: 30$ & $12: 00$ & $0: 30$ & serge type & small & ice shocks \\
\hline $2015 / 4 / 22$ & $16: 25$ & $17: 00$ & $0: 35$ & serge type & small & ice shocks \\
\hline $2015 / 4 / 22$ & $18: 00$ & 19:00 & $1: 00$ & HT, serge type & large & $\mathrm{D}$ \\
\hline $2015 / 4 / 23$ & 2:00 & $3: 10$ & $1: 10$ & serge type & small & \\
\hline $2015 / 4 / 24$ & $11: 30$ & $11: 50$ & $0: 20$ & $\mathrm{HT}$ & small & $\mathrm{D}$ \\
\hline $2015 / 4 / 24$ & $12: 25$ & $12: 45$ & $0: 20$ & $\mathrm{HT}$ & small & $\mathrm{U}$ \\
\hline $2015 / 4 / 24$ & 19:10 & $19: 45$ & $0: 35$ & serge type & small & \\
\hline $2015 / 4 / 26$ & $2: 40$ & $4: 40$ & $2: 00$ & HT, nonlinear & large & flat, slightly down \\
\hline $2015 / 4 / 26$ & $5: 45$ & $7: 15$ & $1: 30$ & HT, nonlinear & large & flat, slightly down \\
\hline $2015 / 4 / 26$ & $9: 15$ & $9: 25$ & $0: 10$ & serge type & small & ice shocks \\
\hline $2015 / 4 / 26$ & $12: 20$ & $12: 45$ & $0: 25$ & serge type & small & ice shocks \\
\hline $2015 / 4 / 26$ & $15: 10$ & $15: 25$ & $0: 15$ & serge type & small & $\mathrm{D}$ \\
\hline
\end{tabular}




\begin{tabular}{lcccccc}
\multicolumn{1}{l}{ Continued } \\
\hline $2015 / 4 / 26$ & $18: 10$ & $19: 15$ & $1: 05$ & serge type, HT & large & D \\
$2015 / 4 / 26$ & $20: 05$ & $20: 15$ & $0: 10$ & serge type & small & ice shocks, D \\
$2015 / 4 / 28$ & $16: 50$ & $17: 10$ & $0: 20$ & serge type & small & ice shocks \\
$2015 / 4 / 28$ & $18: 40$ & $18: 55$ & $0: 15$ & serge type & small & ice shocks, D \\
$2015 / 4 / 28$ & $21: 25$ & $21: 40$ & $0: 15$ & serge type & small & ice shocks, D \\
$2015 / 4 / 28$ & $22: 40$ & $0: 00$ & $1: 20$ & nonlinear & large & flat, slightly down \\
$2015 / 4 / 29$ & $3: 15$ & $3: 40$ & $0: 25$ & serge type & small & ice shocks, D \\
$2015 / 4 / 29$ & $4: 10$ & $11: 00$ & $6: 50$ & nonlinear & large & flat, slightly up \\
$2015 / 4 / 30$ & $7: 50$ & $8: 10$ & $0: 20$ & linear & small & D \\
\hline
\end{tabular}

HT = Harmonic Tremor; Downward frequency content (D); Upward frequency content (U).

observation at SYO and teleseismic detectability is given by [17]; auto-monitoring system for both the seismographs at SYO is also written in [18]. Majority of the events $(\mathrm{N}=39)$ had their duration times more than 15 minutes, which were the experimental definition for dividing tremors and ice shocks around the LHB [17] [18]. In the followings, characteristic waveforms of representative tremors and ice shocks are demonstrated along the time-line on April 2015, dividing into six different date groups. In order to evaluate the relationship between surface environmental changes in the vicinity of LHB particularly cryosphere dynamics, the MODIS satellite images (provided by NASA) were utilized for comparison with the waveform data and spectral densities for each tremor events. It is noticed that each sentence in this paper treats the year on 2015 without any special notification.

\subsection{1-04 April 2015}

From a MODIS satellite image around the LHB on 01 April (Figure 2(a)), in spite of sea-ice condition in offshore of SYO was not clear because of thick clouds spreaded over the area, large cracks having east-to-west orientatoin were identified inside the LHB. The cracks had been spreading out during the succeeding a few days, therefore a separaiton of the northern part of fast sea-ice from the remained southern part of the Bay was recognized in the MODIS image on 04 April (Figure 2(b)). Figure 2(c) and Figure 2(d) represent the seismic waveforms and their power spectral densities of the tremors with harmonic overtones recorded at SYO (06-12 UTC, 04 April, 2015) for both three-component short-period seismographs (HES) and broadband seismographs (STS-1), respectively. Harmonic tremors with downward dipping frequency contents at around few $\mathrm{Hz}$ were identically found around 10:30-12:00 UTC for all components of both the seismographs. These harmonic tremors were considered to be originated by "crevassing events" along the large cracks inside fast sea-ice of LHB.

\subsection{7-11 April 2015}

On the basis of MODIS satellite images, a massive volume of fast sea-ice in northwestern part of LHB was discharged on 07 April, resulted in spreading out the open sea area in the middle of the Bay (Figure 3(a)). A series of serge type 
tremors were identical around 03:10-04:30 UTC for all the components of both short-period and broadband seismographs (Figure $3(\mathrm{~b})$ and Figure $3(\mathrm{c})$ ). It is noted that the surface waves of teleseismic events were overrapped around 01:3002:00 UTC only in the braodband seismographs. These serge type tremors were condidered to be generated by the "discharge events" of the fast sea-ice in LHB. After three days, a MODIS satellite image on 11 April indicated a large volume

MODIS satellite image around LHB, 20150401

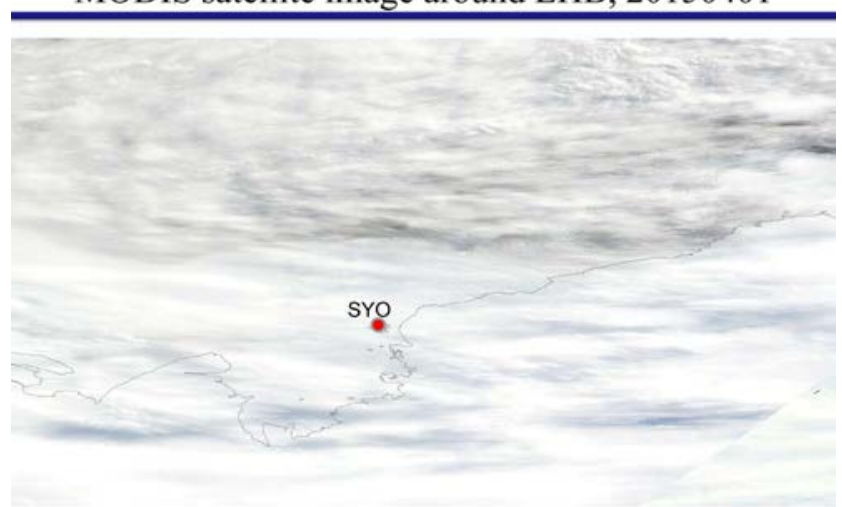

(a)

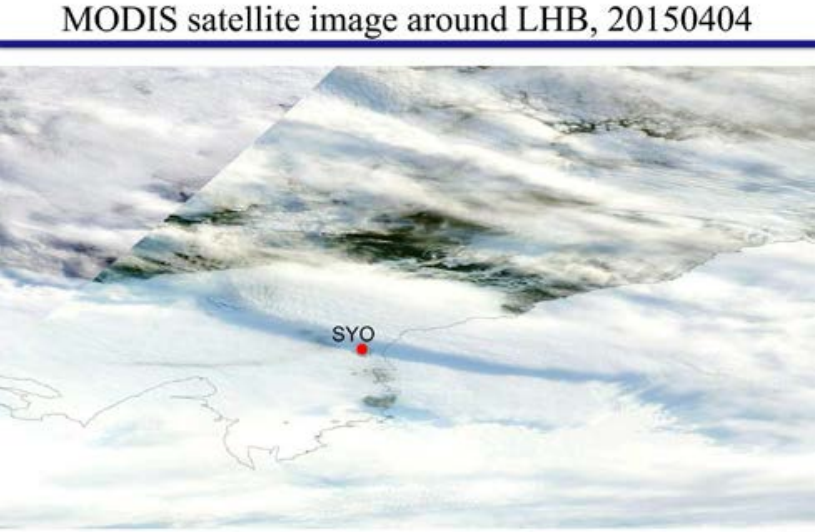

(b)

HF harmonic tremor recorded at SYO, 20150404
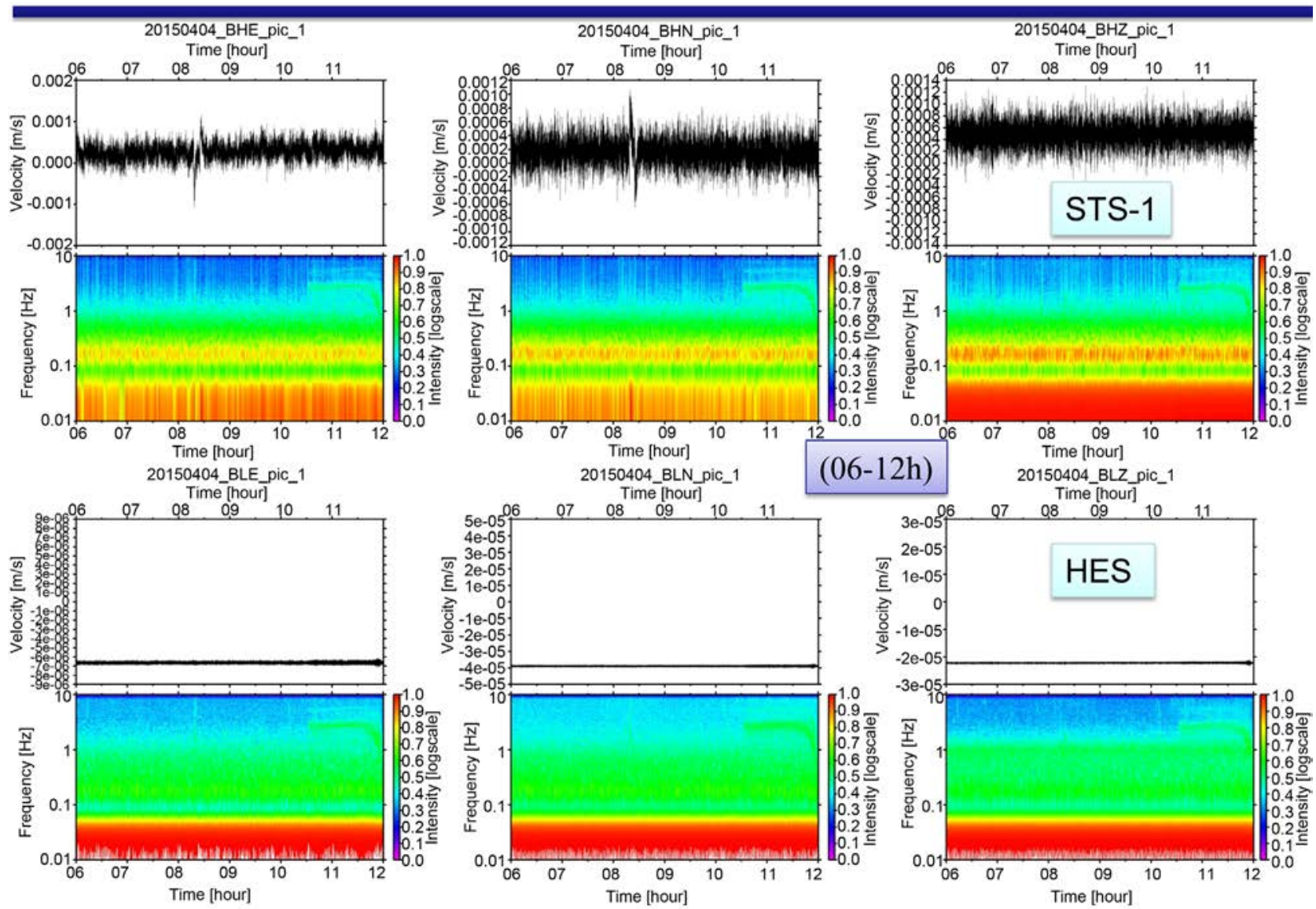

(c) 


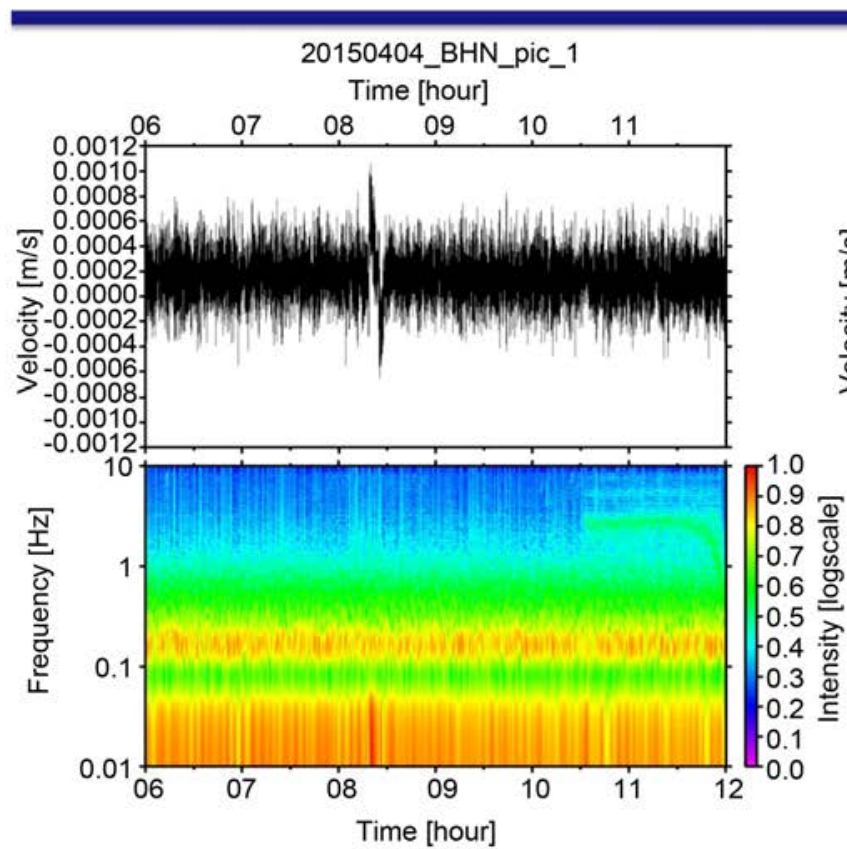

STS-1 (broadband), NS comp.

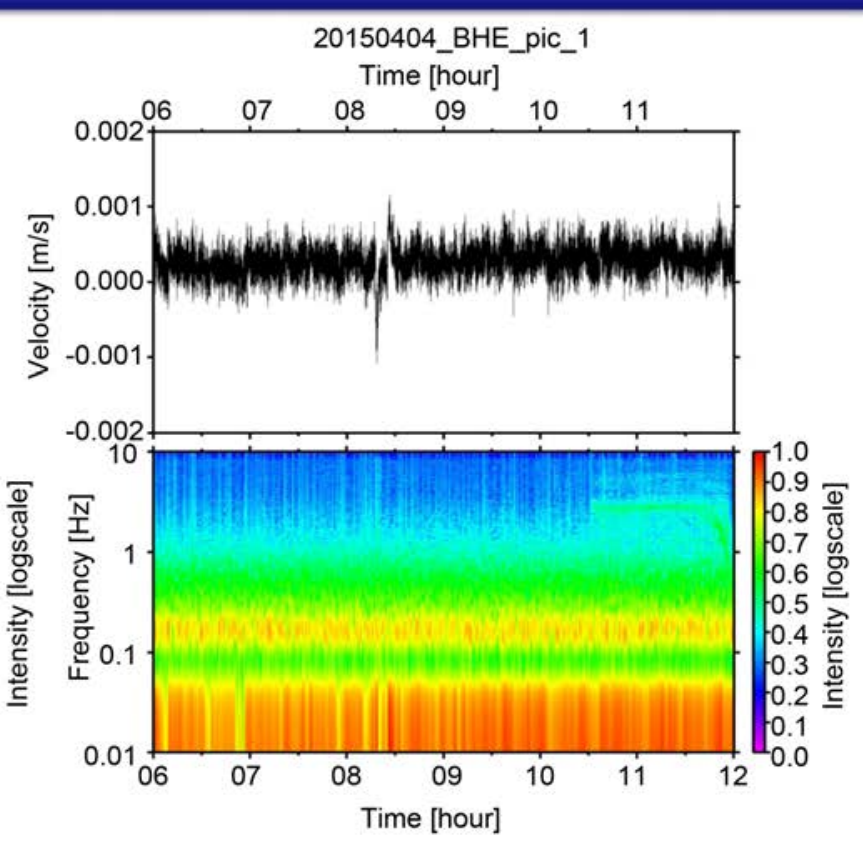

STS-1 (broadband), UD comp.

(d)

Figure 2. (a) MODIS satellite image around LHB on 01 April, 2015. Sea-ice condition was not clear because of the clouds covered over the region, however, the EW trending cracks inside the Bay was recognized. (b) MODIS satellite image around LHB on 04 April, 2015. Separaiton of the northern part of fast sea-ice from the remained southern part of the Bay was identified. (c) Seismic waveforms and their power spectral densities of seismic tremors with harmonic overtones recorded at SYO (06-12 UTC, 04 April, 2015) for both three-component short-period seismographs (HES; lower panels) and broadband seismographs (STS-1; upper panels), respectively. Harmonic tremors with donward dipping characteristics in frequency contents were found around 10:30-12:00 UTC for all the components of both seismographs. (d) Seismic waveforms and their power spectral densities of the harmonic tremors recorded at SYO (06-12 UTC, 04 April, 2015; the same event in Figure 2(c)) for two-component broadband seismographs (STS-1). These tremors were considered to be originated by the "crevassing events" inside fast sea-ice of the Bay.

(one third area) of fast sea-ice in the northwestern part of LHB had been discharged, resulted in increasing the open sea area in the middle of the Bay (Figure 3(d)). Three large icebergs were recognized in the northern open sea area of the Bay, which had been drifted from the eastward offshore of Enderby Land to LHB.

\subsection{4-15 April 2015}

On 14 April, an iceberg (the same one of the middle portion in Figure 3(d)) collided with the northern edge of the fast sea-ice of LHB, in spite of a significant volume of clouds covered the area (Figure 4(a)). Figure 4(b) and Figure 4(c) demonstrate the waveforms and their power spectral densities of seismic tremors recorded at SYO (18-24 UTC, 14 April, 2015) for both short-period and broadband seismographs. A couple of serge type tremors were identically recognized 


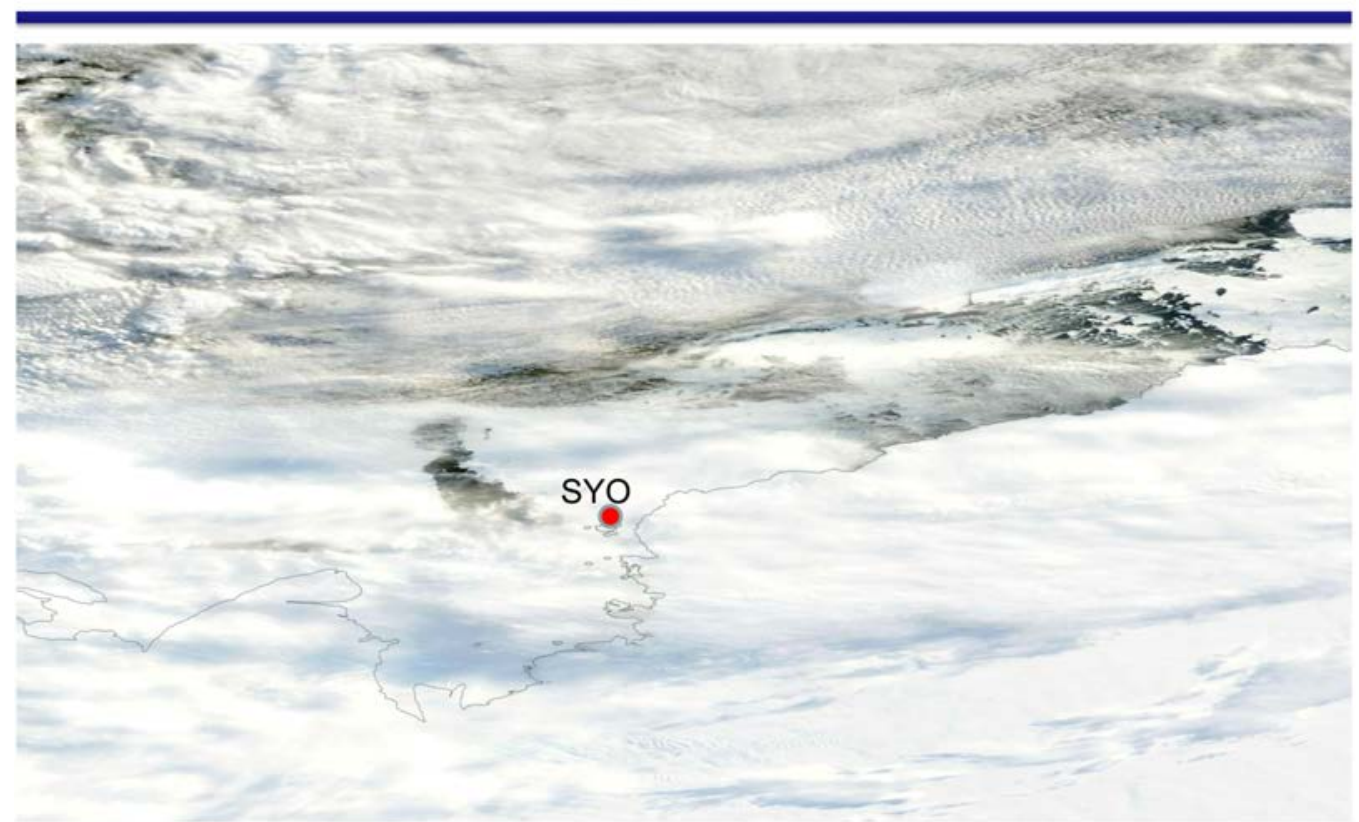

(a)

HF harmonic tremor recorded at SYO, 20150407
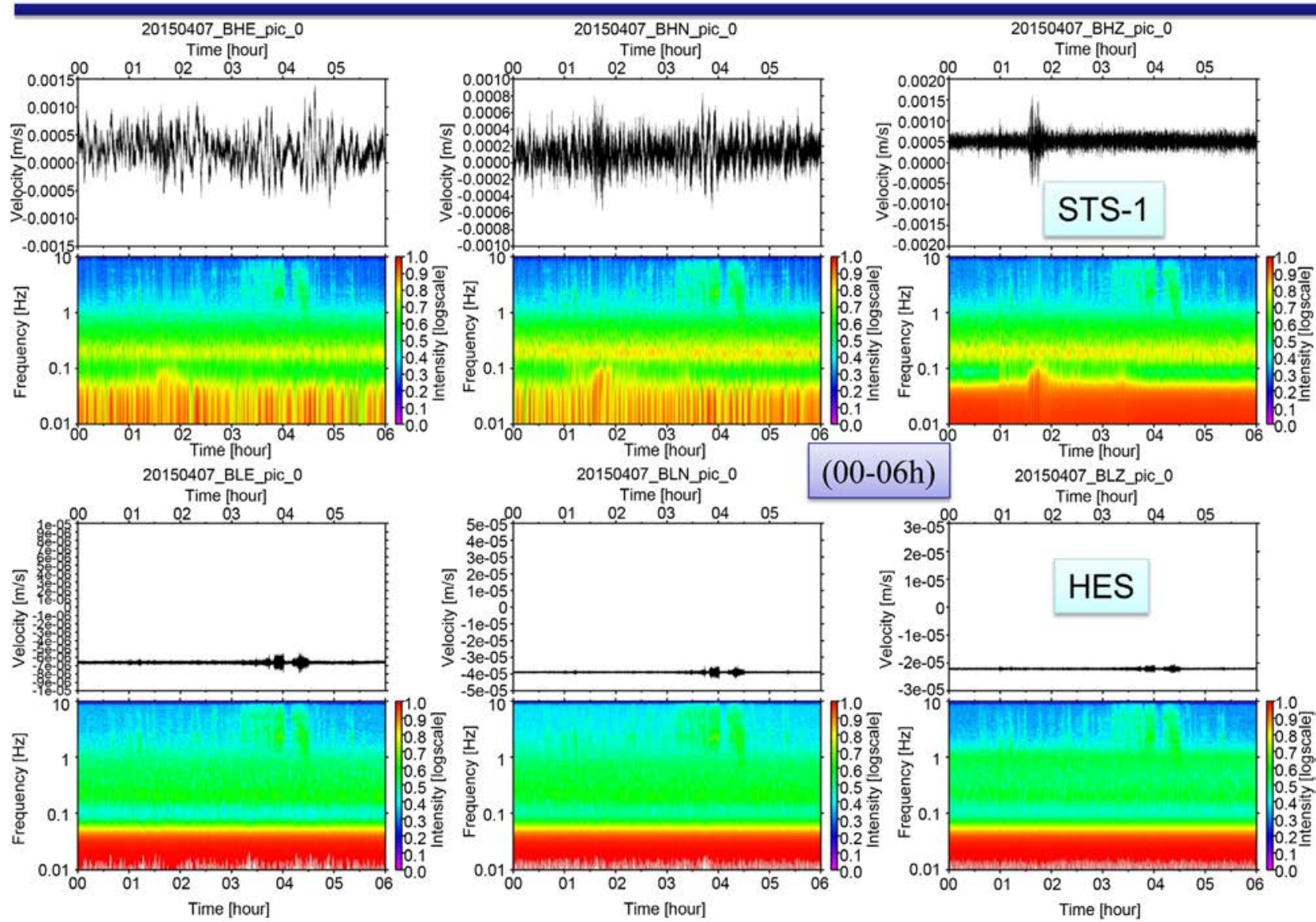

Time

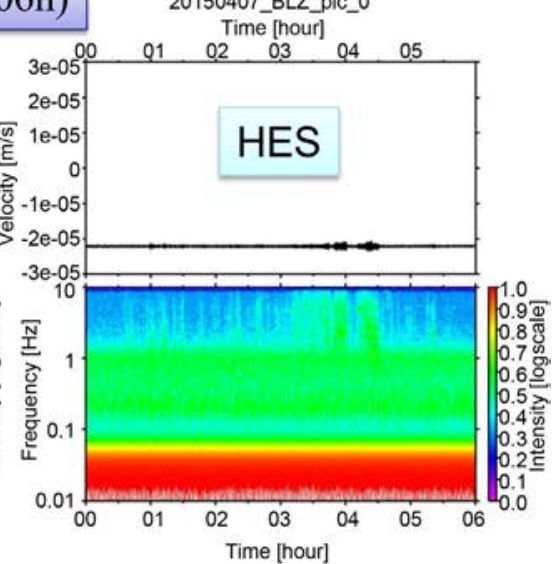

(b) 


\section{High-frequency harmonic tremor recorded \\ at Syowa Station, 20150407 (00-06h)}

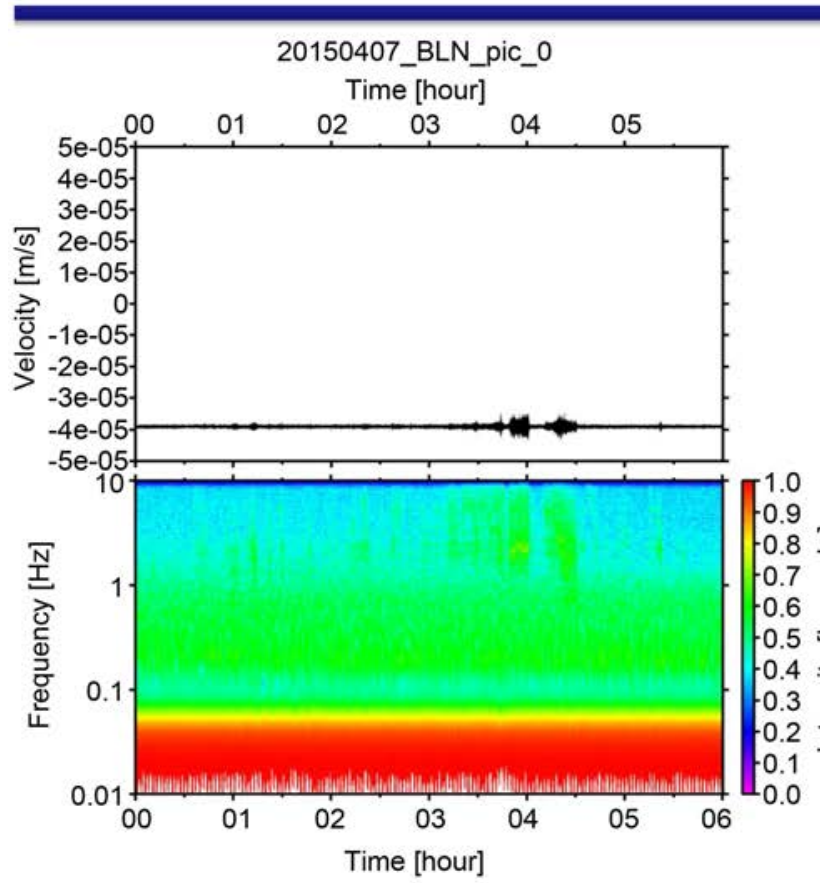

HES (short period), NS comp.

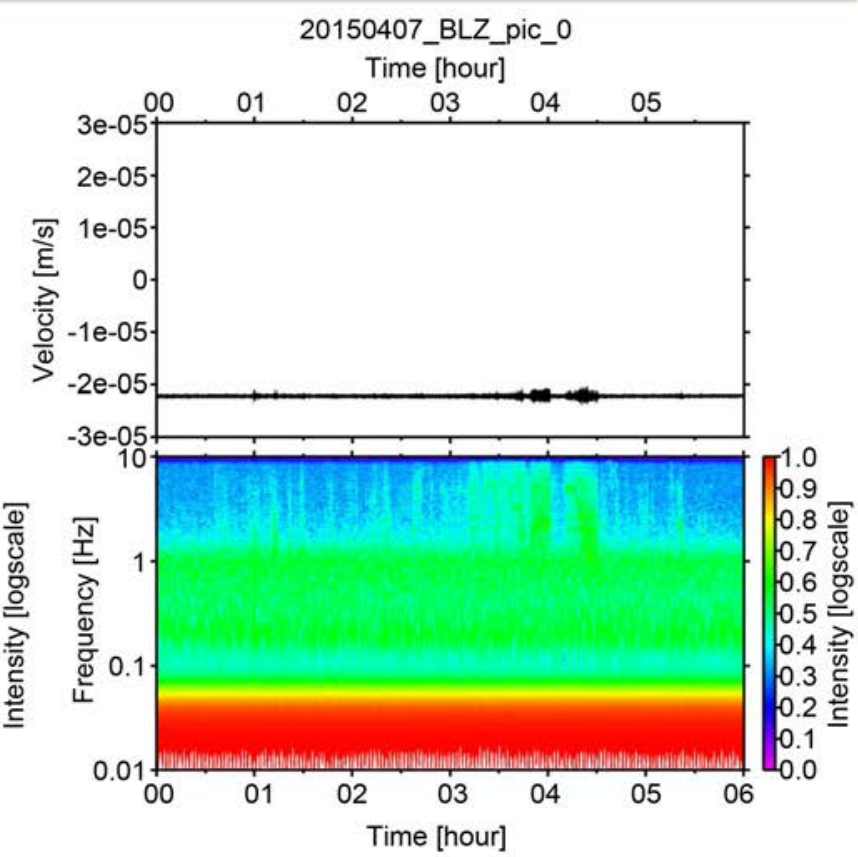

HES (short period), UD comp.

(c)

MODIS satellite image around LHB, 20150411

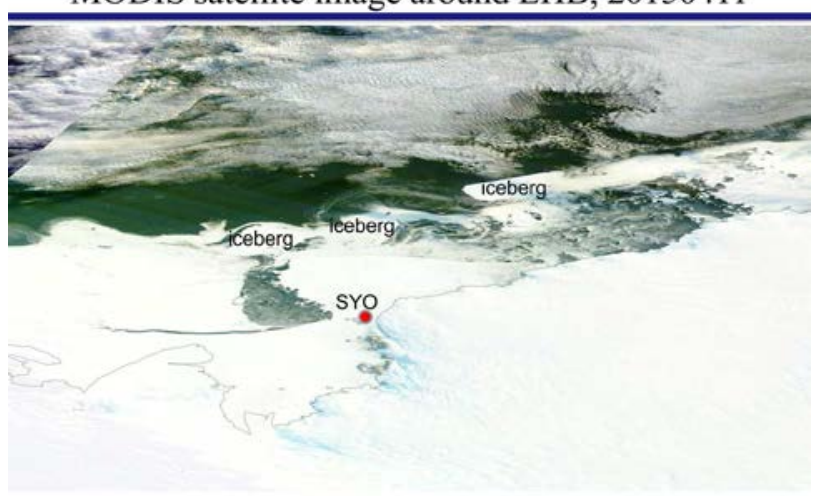

(d)

Figure 3. (a) MODIS satellite image around LHB on 07 April, 2015. A large volume of fast sea-ice in the northwestern part of LHB had been discharged, resulted in spreading out the open sea area in the middle of the Bay. (b) Seismic waveforms and their power spectral densities of seismic tremors recorded at SYO (00-06 UTC, 07 April, 2015) for both three-component short-period seismographs (HES; lower panels) and broadband seismographs (STS-1; upper panels), respectively. A series of serge type tremors was found around 03:10-04:30 UTC for all the components of both seismographs. It is noted that the surface waves of teleseismic events were recognized around 01:30-02:00 UTC only in braodband seismographs. (c) Seismic waveforms and their power spectral densities of the seismic tremors recorded at SYO (00-06 UTC, 07 April, 2015; the same event in Figure 3(b)) for two-component short-period seismographs (HES). A series of serge type tremors were recognized around 03:10-04:30 UTC. These tremors were condidered to be generated by the "discharge events" of the fast sea-ice in LHB. (d) MODIS satellite image around LHB on 11 April, 2015. A large volume (one third area) of fast sea-ice in the northwestern part of LHB had been discharged, resulted in increasing the open sea area in the middle of the Bay. Three large icebergs were also idenfied in the northern part of LHB, which were drifted from the westward offshore of Enderby Land, East Antarctica. 


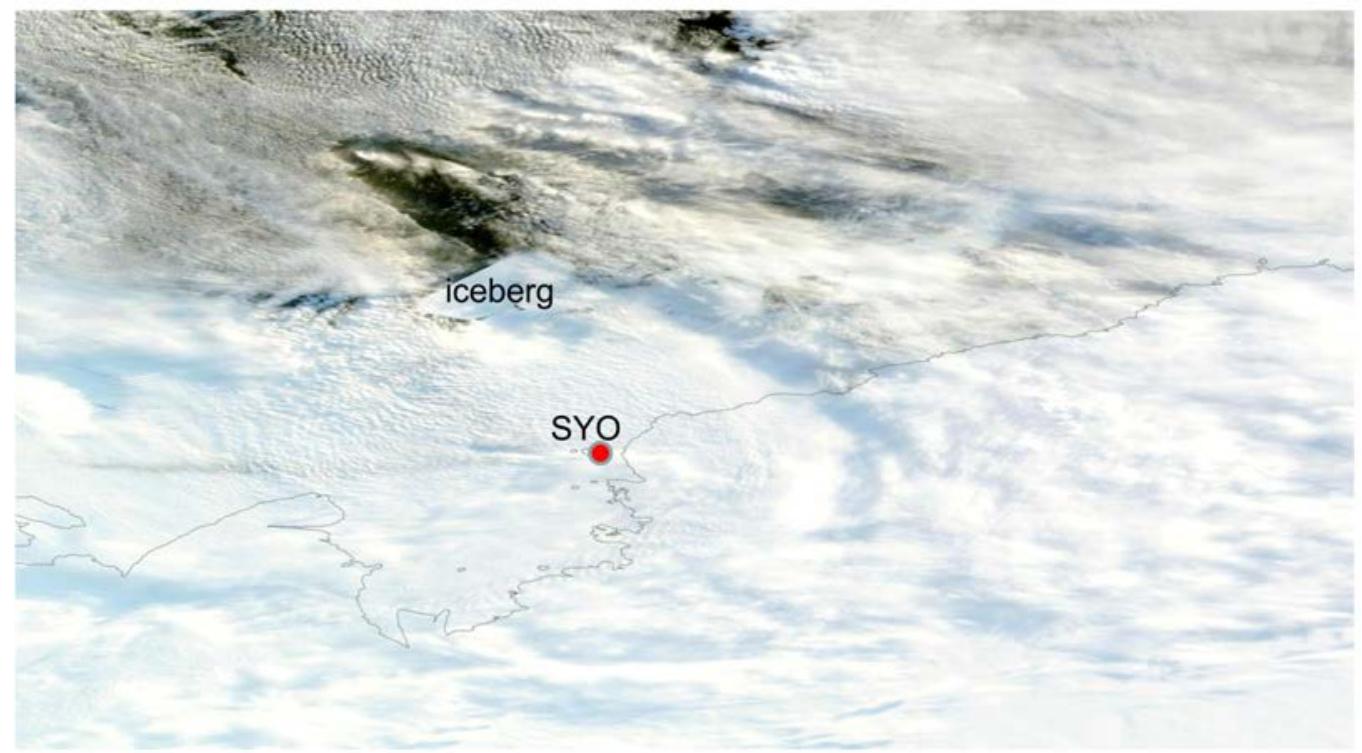

(a)

HF harmonic tremor recorded at SYO, 20150414
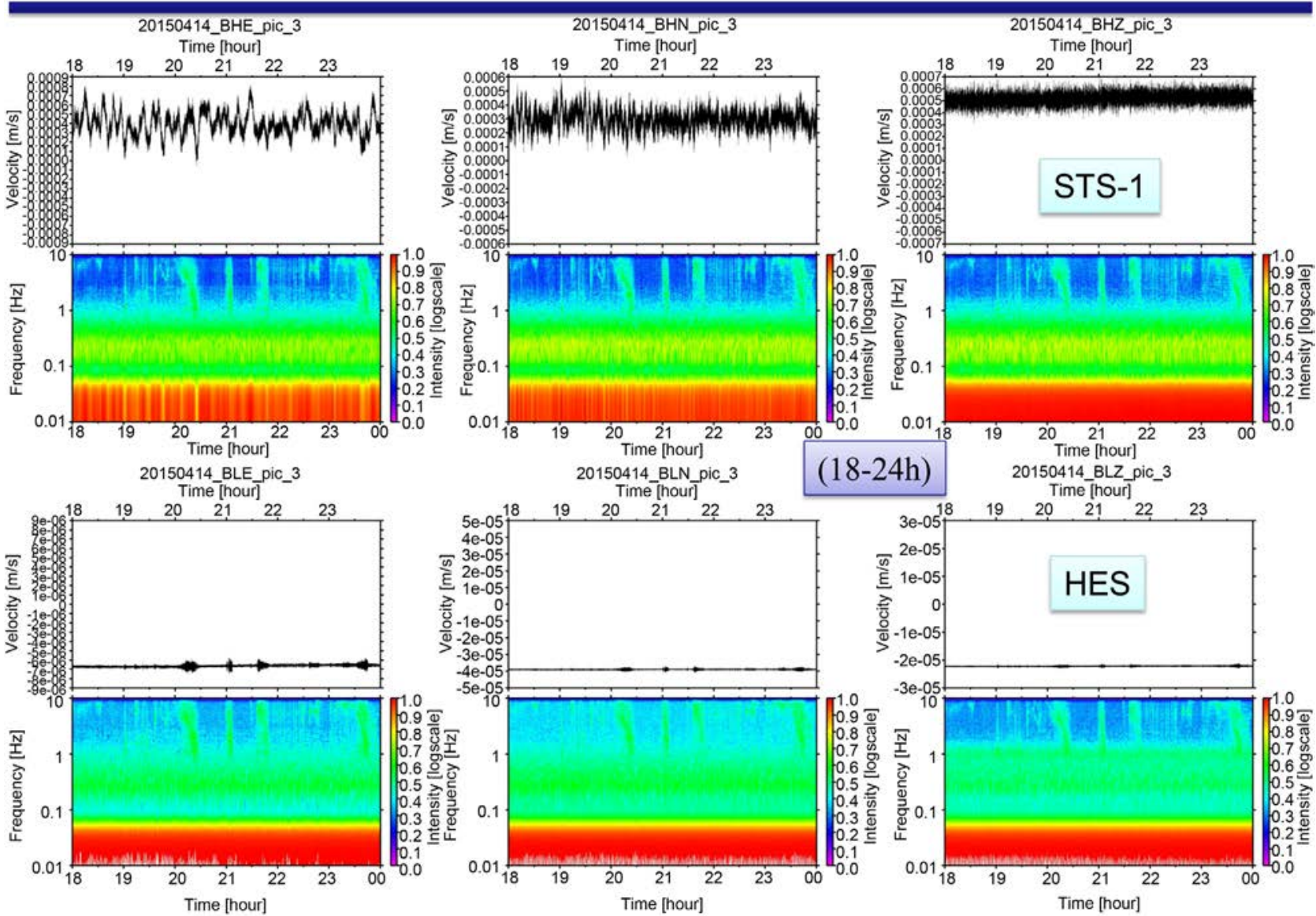

(b) 


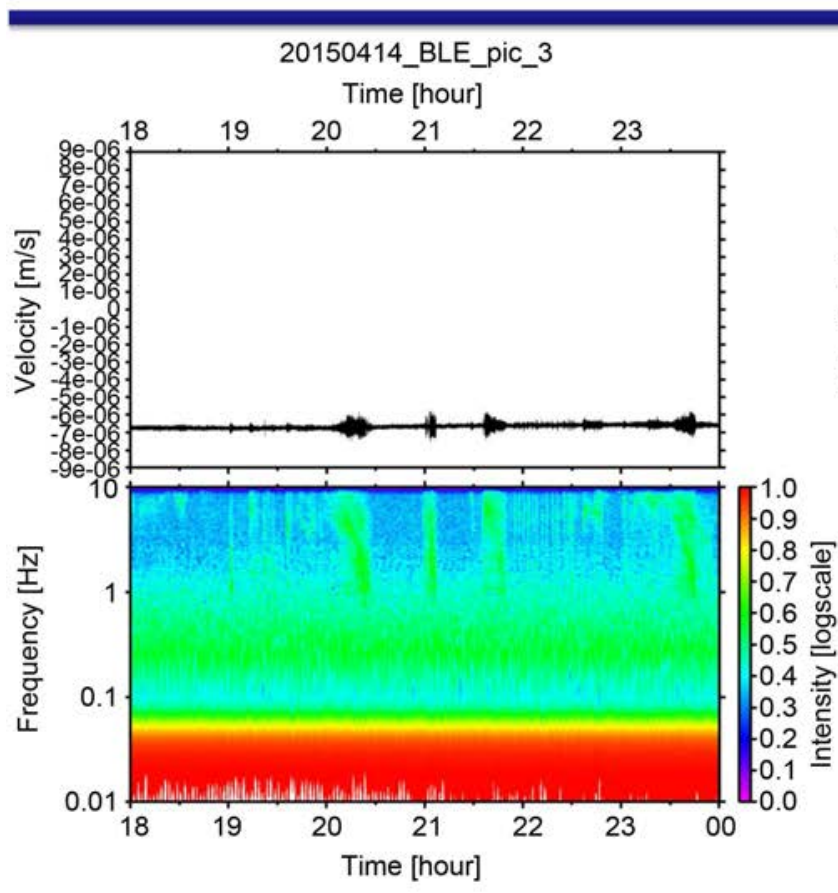

HES (short period), EW comp.

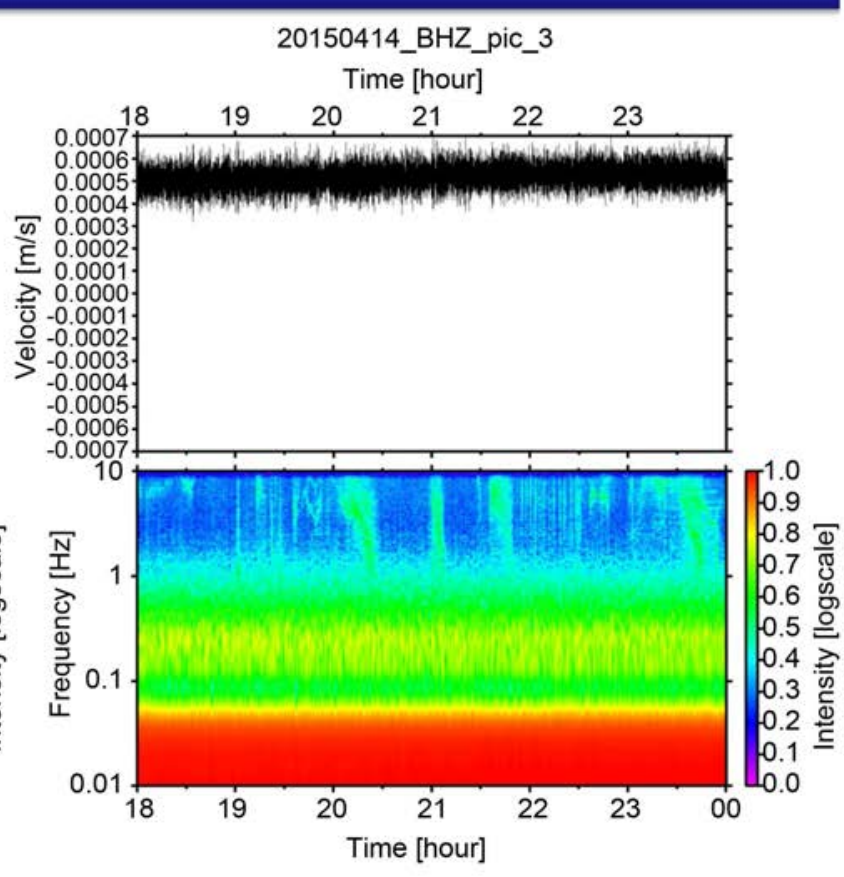

STS-1 (broadband), UD comp.

(c)

MODIS satellite image around LHB, 20150415

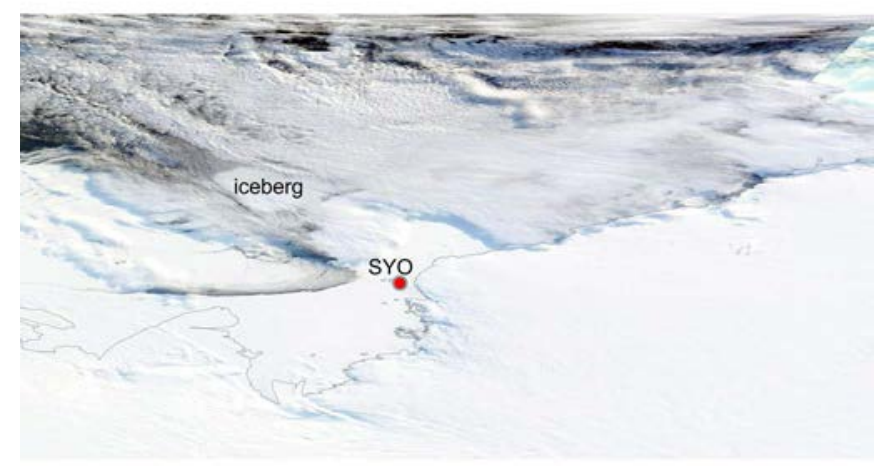

(d)

Figure 4. (a) MODIS satellite image around LHB on 14 April, 2015. An iceberg (the same of the middle one in Figure 3(d)) collides with the northern edge of the fast sea-ice, in spite of clouds covered the area. (b) Seismic waveforms and their power spectral densities of tremors recorded at SYO (18-24 UTC, 14 April, 2015) for both three-component short-period (HES; lower panels) and broadband seismographs (STS-1; upper panels). A couple of serge type tremors was recognized during the six hours for all the components of both seismographs. (c) Seismic waveforms and their power spectral densities of the seismic tremors recorded at SYO (18-24 UTC, 14 April, 2015; the same event in Figure 4(b)) for horizontal component of short-period seismographs (HES) and vertical component of broadband seismographs (STS-1). A couple of serge type tremors was simulteneously recognized for both the seismographs. These tremors were concidered to be generated by the "collision events" between the icebergs and the edge of fast sea-ice of the Bay. (d) MODIS satellite image around the LHB on 15 April, 2015. An iceberg (the same of the middle one in Figure 3(d), and the one in Figure 4(a)) had already collided with the edge of fast sea-ice in LHB and migrated westward from the position in Figure 4(a). Almost half of the fast sea-ice had been discharged until the day. 
during these six hours for all components of both seismographs. These tremors were concidered to be generated by "collision events" between the iceberg and the edge of fast sea-ice of LHB. At next day on 15 April (Figure 4(d)), an iceberg (the same of the middle one in Figure 3(d), and the same one in Figure 4(a)) had already collided with the edge of fast sea-ice of LHB and migrated westward from the position in Figure 4(a). Almost half of the fast sea-ice had been discharged until the day.

\subsection{8-19 April 2015}

On 18 April, an iceberg (the same as of the middle one in Figure 3(d), and the one in Figure 4(a) and Figure 4(d)) had drifted to the west of LHB, followed by a next iceberg arrived at the northern edge of the fast sea-ice (north direction about $100 \mathrm{~km}$ distance from SYO) (Figure 5(a)). Discharged sea-ice region and open sea area had been spreaded out after the condition in Figure 4(d). Figure 5(b) indicates a MODIS image around LHB on 19 April. Position of icebegrs and fragments of fast sea-ice on 18 April are represented by gray (light blue) hatched areas. Boundary line (northern edge) of fast sea-ice area is indicated by red dashed line. In Figure 5(b), the colored circles (number of events; $\mathrm{N}=21$ ) are the source location estimated by infrasound arrays deploying at SYO and S16

MODIS satellite image around LHB, 20150418

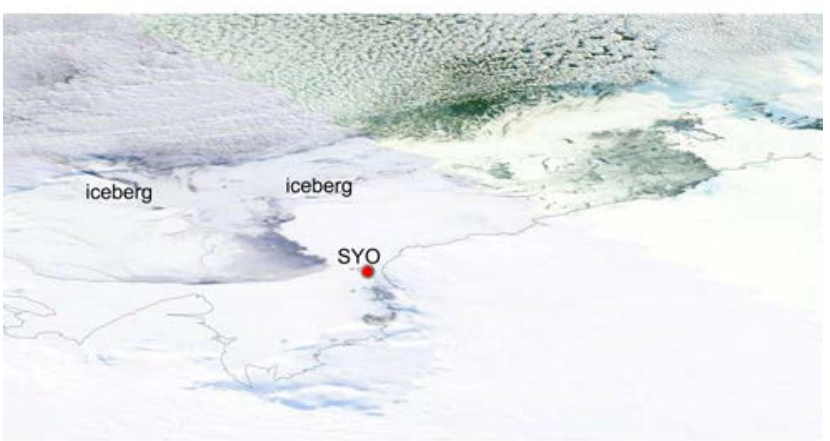

(a)
MODIS satellite image around LHB, 2015 0418-0419

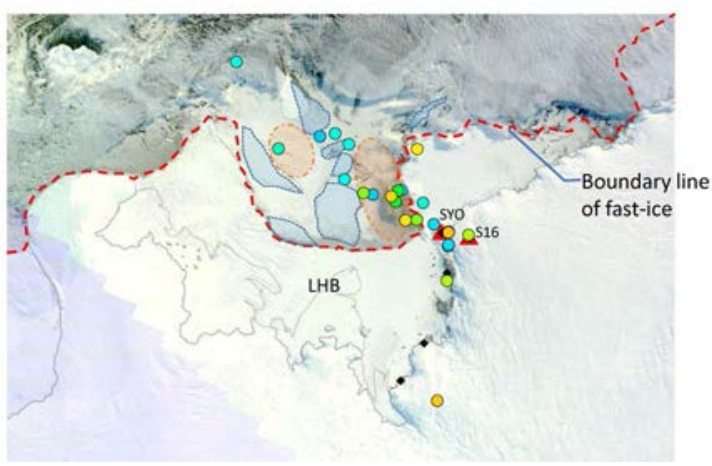

(b)

MODIS satellite image around LHB, 20150422

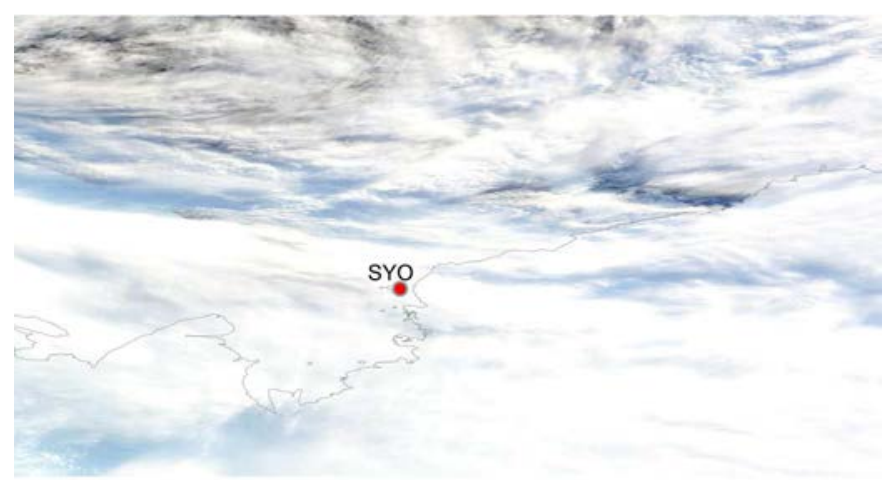

(c) 

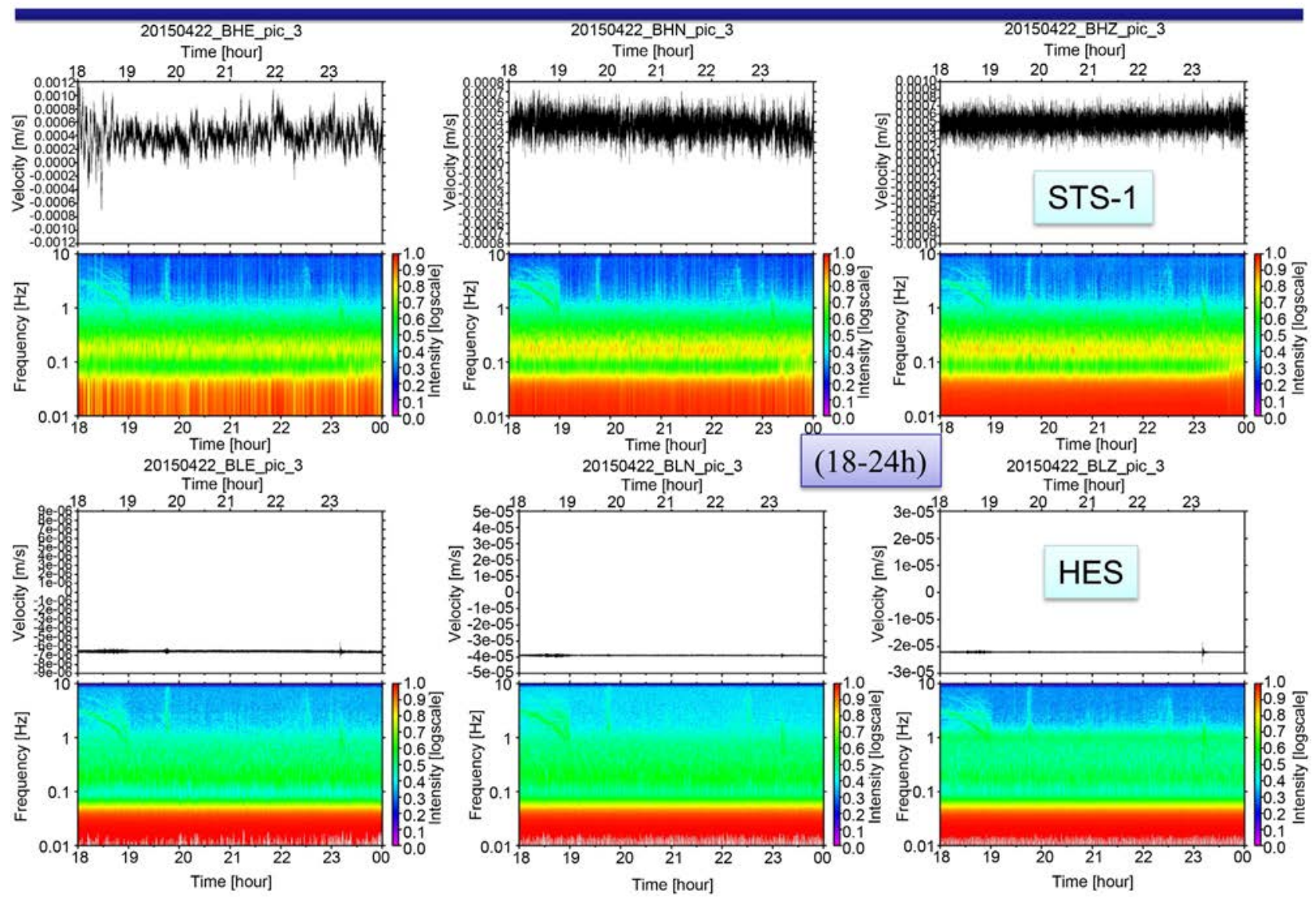

(d)

Figure 5. (a) MODIS satellite image around LHB on 18 April, 2015. The iceberg (the same of the middle one in Figure 3(d), and the one in Figure 4(a) and Figure 4(d)) had drifted to the west of the Bay, and the next iceberg arrived at the northern edge of the fast sea-ice (north direction from SYO). Discharged sea-ice and open sea area had been spread out after Figure 4(d). (b) MODIS satellite image around LHB on 18-19 April, 2015. Positions of icebergs and fragments of fast sea-ice on 18 April are represented by gray dashed areas. Boundary line of fast sea-ice is indicated by red dashed line. The colored circles are the source location estimated by infrasound arrays deploying at SYO and S16 (red triangles) during one day on 18 April (modified after [19]). Colors of the source location circles correspond the source origin time from the beginning of the day (from blue, green, yellow and orange). These events appeared to be generated by the "crashing movement" between fragnemtation of fast sea-ice and packed sea-ice, together with "calving events" of glaciers/ice-streams at the edge of continental ice-sheet. (c) MODIS satellite image around LHB on 22 April, 2015. As the clouds covered the LHB then sea-ice conditions could not be caught exactly. (d) Seismic waveforms and their power spectral densities of the tremors recorded at SYO (18-24 UTC, 22 April, 2015) for both three-component short-period (HES; lower panels) and broadband seismographs (STS-1). Harmonic tremors with donward dipping characteristics in frequency contents were found around 18-19 UTC for all the components of both seismographs. These tremors were considered to be generated by the "collision events" between the icebergs and sea-ices of the Bay.

(red triangles in the figure) during one day on 18 April [19]. Colors of the source location circles correspond the source origin time from the beginning of the day. These detected events by infrasound analysis appeared to be generated by "crashing movement" between fragnemtation of fast sea-ice and packed sea-ice, in northwestward orientation from the arrays. In addition, five events were located at the edge of continental ice-sheet by the infrasound arrays, which appeared to be 
"calving events" of glaciers/ice-streams at a margin of the continent. However, these infrasound events on 18 April could not be detected by SYO seismographs, because of a single station allinment without any array configuration.

\subsection{2-26 April 2015}

In spite of thick clouds covered over LHB on 22 April (Figure 5(c)), harmonic tremors with downward dipping characteristics of frequency contents were found around 18-19 UTC of the day for all the components of both short-period and broadband seismographs (Figure 5(d)). These harmonic tremors were assumed to be originated by "collision events" among the cryosphere environment such as the icebergs, sea-ices of the Bay. The downward dipping (griding down) chracteristics of frequency contents in the tremors can be explained by a stopping movement associated with asperities within the colliding medium [20] [21].

From a MODIS image around LHB on 24 April (Figure 6(a)), discharged fast sea-ice and open sea area in the northwest part of the Bay had further been spread out after 19 April (Figure 5(b)). On 26 April, in spite of the clouds covered over LHB (Figure 6(b)), a series of non-linear type tremors were simulteneously recognized after 02:40 UTC for all components of both types of seismographs (Figure 6(c) and Figure 6(d)). These tremors were considered to be generated by "crashing movement" among fragmemtation of fast sea-ice and packed seaice in the Bay.

\subsection{8-29 April 2015}

Several serge type tremors were recognized for all components of both seismographs on 28 April (Figure 7(b)), in spite of the clouds covered over LHB at the day (Figure $7(\mathrm{a})$ ). Figure $7(\mathrm{c})$ and Figure $7(\mathrm{~d})$ represent the waveforms and their power spectral densities of the tremors recorded at SYO (06-12 UTC, 29 April, 2015). Long-durating and non-linear harmonic tremors were clearly traced for all components of both seismographs. These harmonic tremors were presumably concidered to be generated by "a kind of collision mechanism within cryosphere" accosiated with fragnemts of fast sea-ice and surrounding packed sea-ice in the Bay. It is noticed that a MODIS image on 29 April was also covered by thick clouds and partial areas of LHB were lacked for the image.

\section{Discussion}

Figure 8 presents power spectral densities of infrasound data recorded at SYO (one of the array sites; C1; see the details in [19]) during a whole month of April 2015. High amplitudes of the spectral densities appeared in stormy/windy days. Several non-linear harmonic overtoned signals are also identified in the frequency range over $25 \mathrm{~Hz}$. A reltionship between detection number of seismic tremors and infrasound spectral densities appearred to be an opposite feature, which means the tremors were rather difficult to detect when these stormy/ 
windy days. This trends can be traced by a comparison of the tremors list (Table 1) and Figure 8. In this regard, several kinds of cryosphere sources for generating seismic tremors (collision, calving, crevassing, crashing, others) are appeared to be independent of wheather condition, resulting that seismic tremors treated in this paper could be identified during less stormy/windy (relatively fine whether) days. Regarding the relationship between harmonic overtones found in

MODIS satellite image around LHB, 20150424

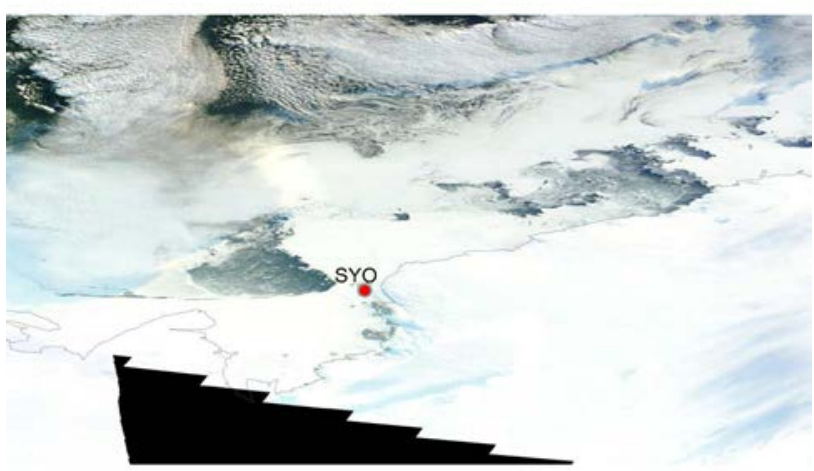

(a)
MODIS satellite image around LHB, 20150426

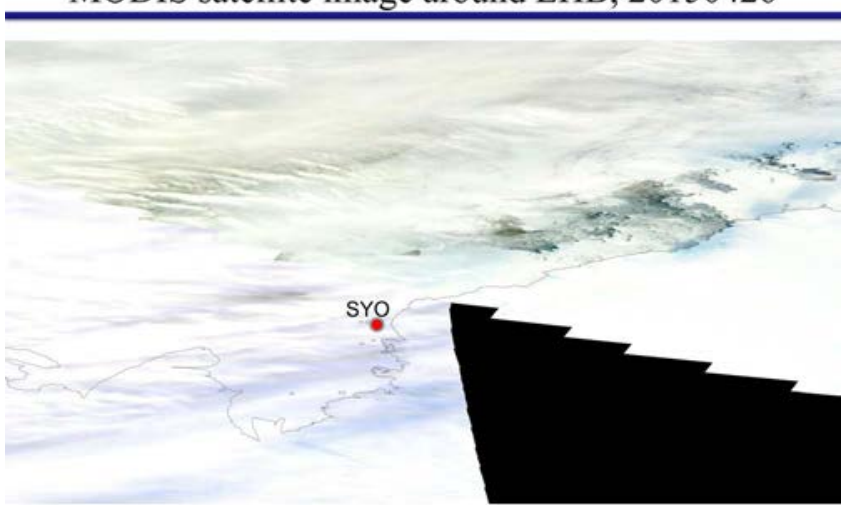

(b)

HF harmonic tremor recorded at SYO, 20150426
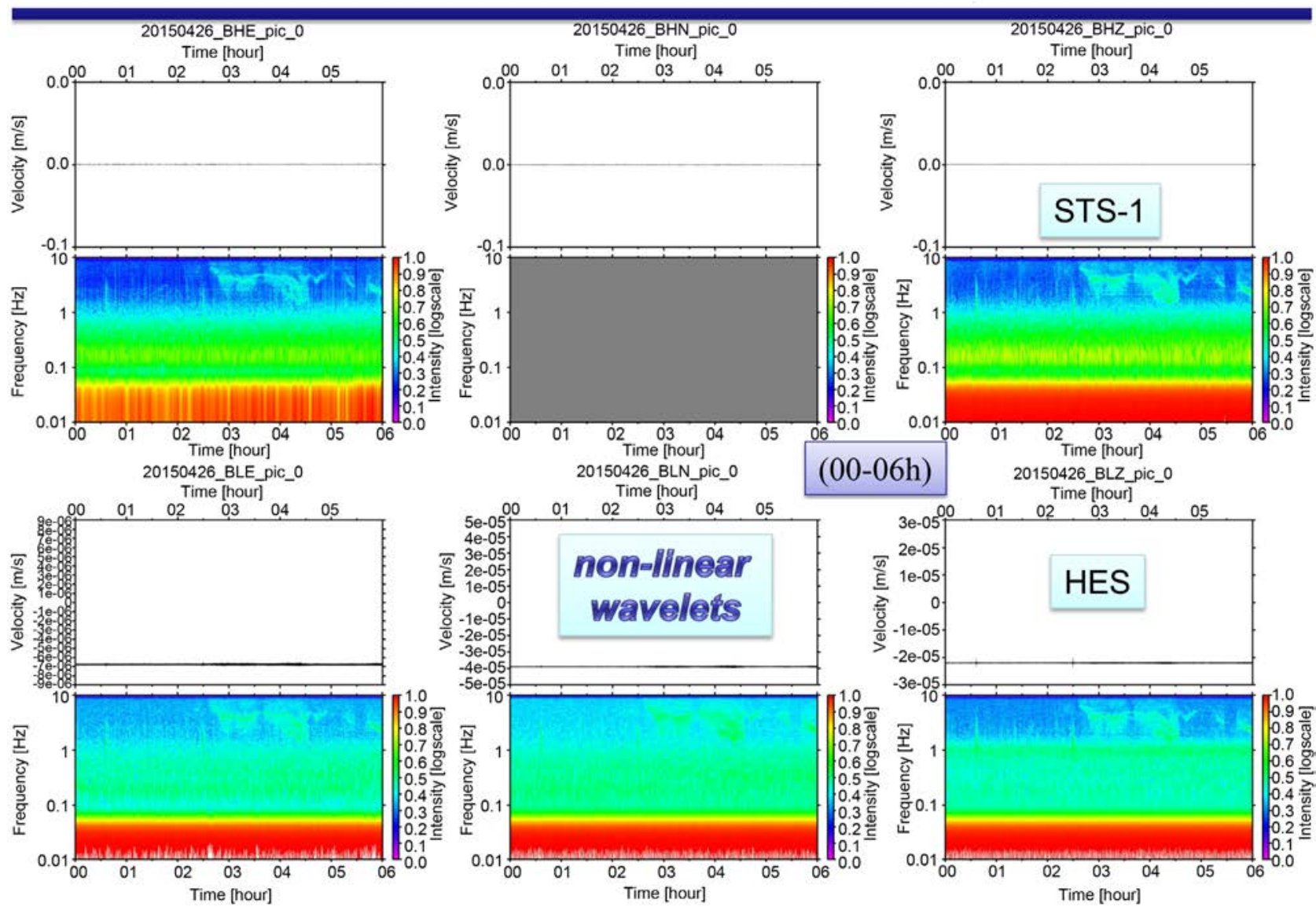

(c) 


\section{High-frequency harmonic tremor recorded \\ at Syowa Station, $20150426(00-06 \mathrm{~h})$}

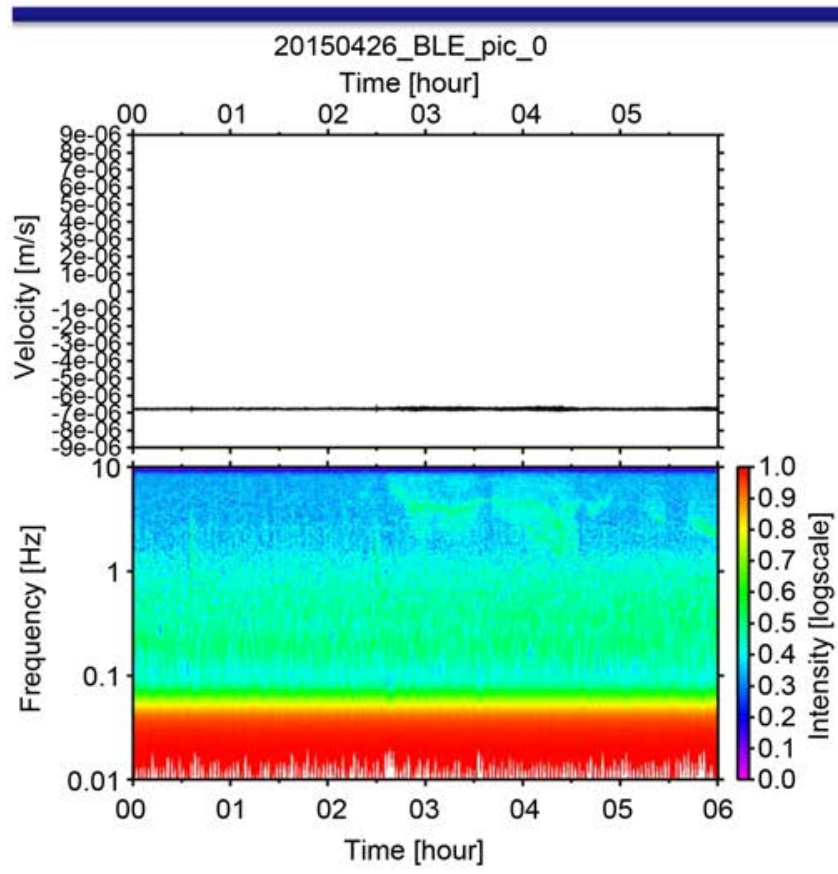

HES (short period), EW comp.

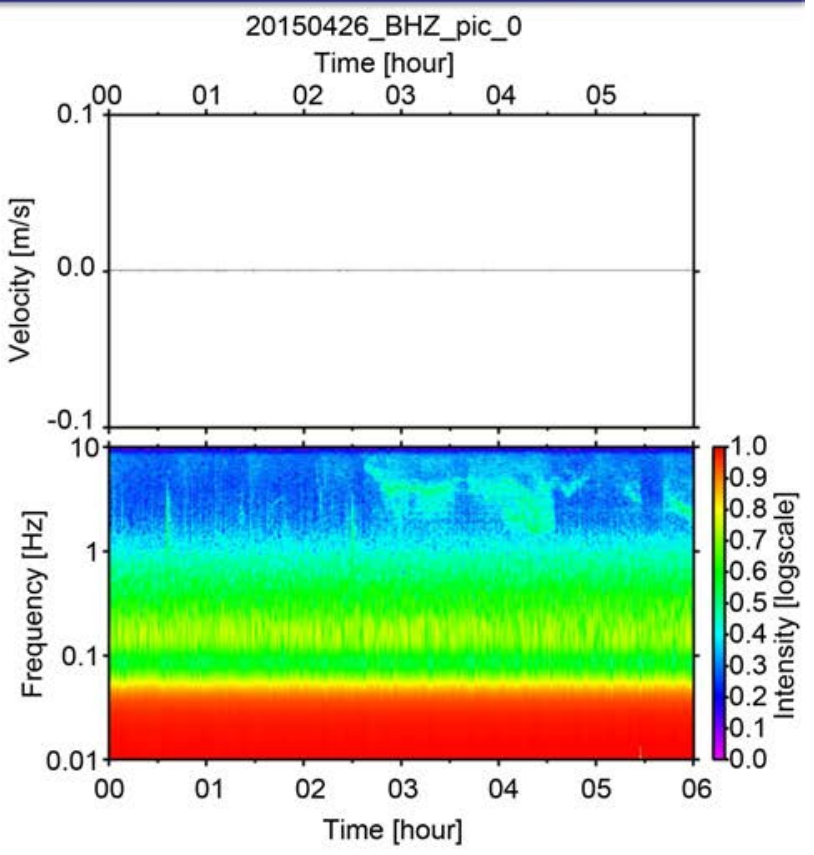

STS-1 (broadband), UD comp.

(d)

Figure 6. (a) MODIS satellite image around LHB on 24 April, 2015. Discharged fast sea-ice and open sea area in the northwest part of the Bay had further been spread out after the date shown in Figure 5(b). (b) MODIS satellite image around LHB on 26 April, 2015. As the clouds covered the LHB then sea-ice conditions could not be checked exactly. (c) Seismic waveforms and their power spectral densities of tremors recorded at SYO (00-06 UTC, 26 April, 2015) for both three-component short-period (HES; lower panels) and broadband seismographs (STS-1). A series of non-linear type tremors was recognized after 02:40 UTC for all the components of both seismographs. (It is noticed that the power spectral densities of NS component cannot adequately by calculated for STS-1; the upper-middle panel). (d) Seismic waveforms and their power spectral densities of tremors recorded at SYO (00-06 UTC, 26 April, 2015; the same event in Figure 6(c)) for horizontal component EW of short-period seismographs (HES) and vertical component of broadband seismographs (STS-1). A series of non-linear type tremors was simulteneously recognized for both the seismographs. These tremors were concidered to be generated by "crashing movement" between fragnemtation of fast sea-ice and packed sea-ice in the Bay.

infrasound data and seismic tremors, there are no confident evidence of their correlation to each other. The harmonic overtones in infrasound data have higher (over $25 \mathrm{~Hz}$ ) frequency than seismic tremors (less than $10 \mathrm{~Hz}$ ), moreover, the appearent date/time did not coincident to each other during the days on April 2015. Therefore, the harmonic overtones in infrasound data were considered to had more local origins, presumably relating "katabatic winds" which had been arriving from the continent. Similar discussion about the origin of high-frequency harmonic overtones in infrasound data was given by [22].

Some of the newly found seismic tremors attribute characteristics of strong harmonic overtones, in their frequency content over $1 \mathrm{~Hz}$, representing nonlinear features having downward frequency contents with duration times from 
MODIS satellite image around LHB, 20150428

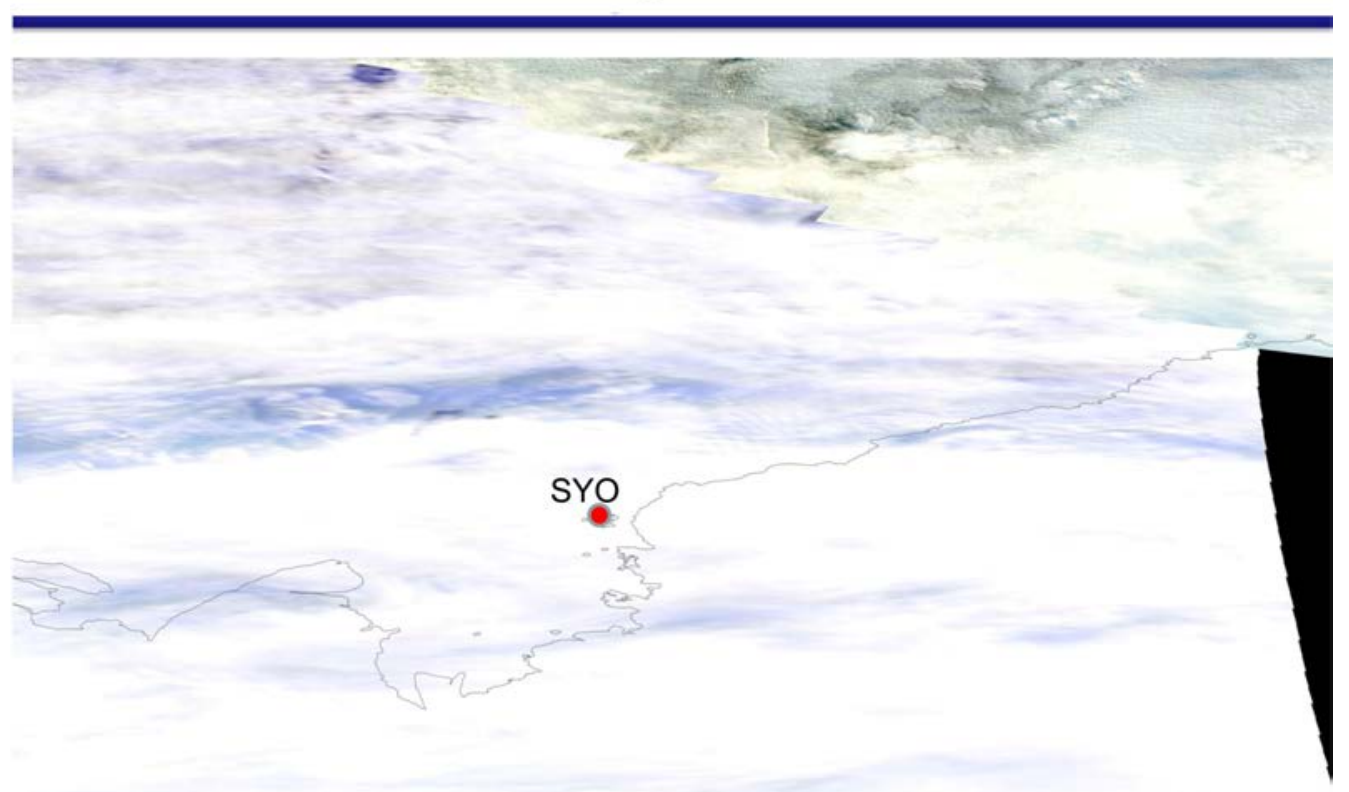

(a)

HF harmonic tremor recorded at SYO, 20150428
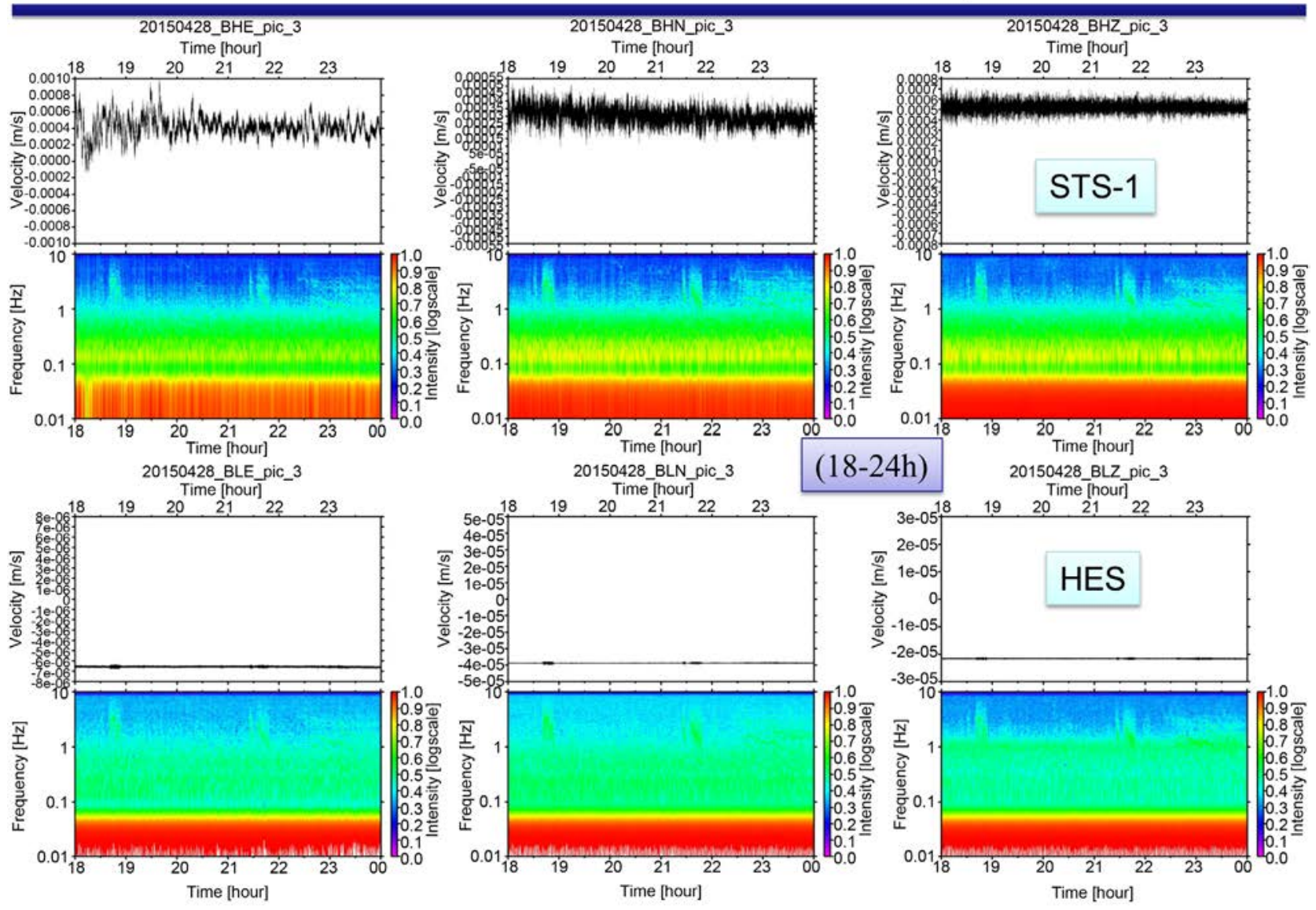

(b) 
HF harmonic tremor recorded at SYO, 20150429
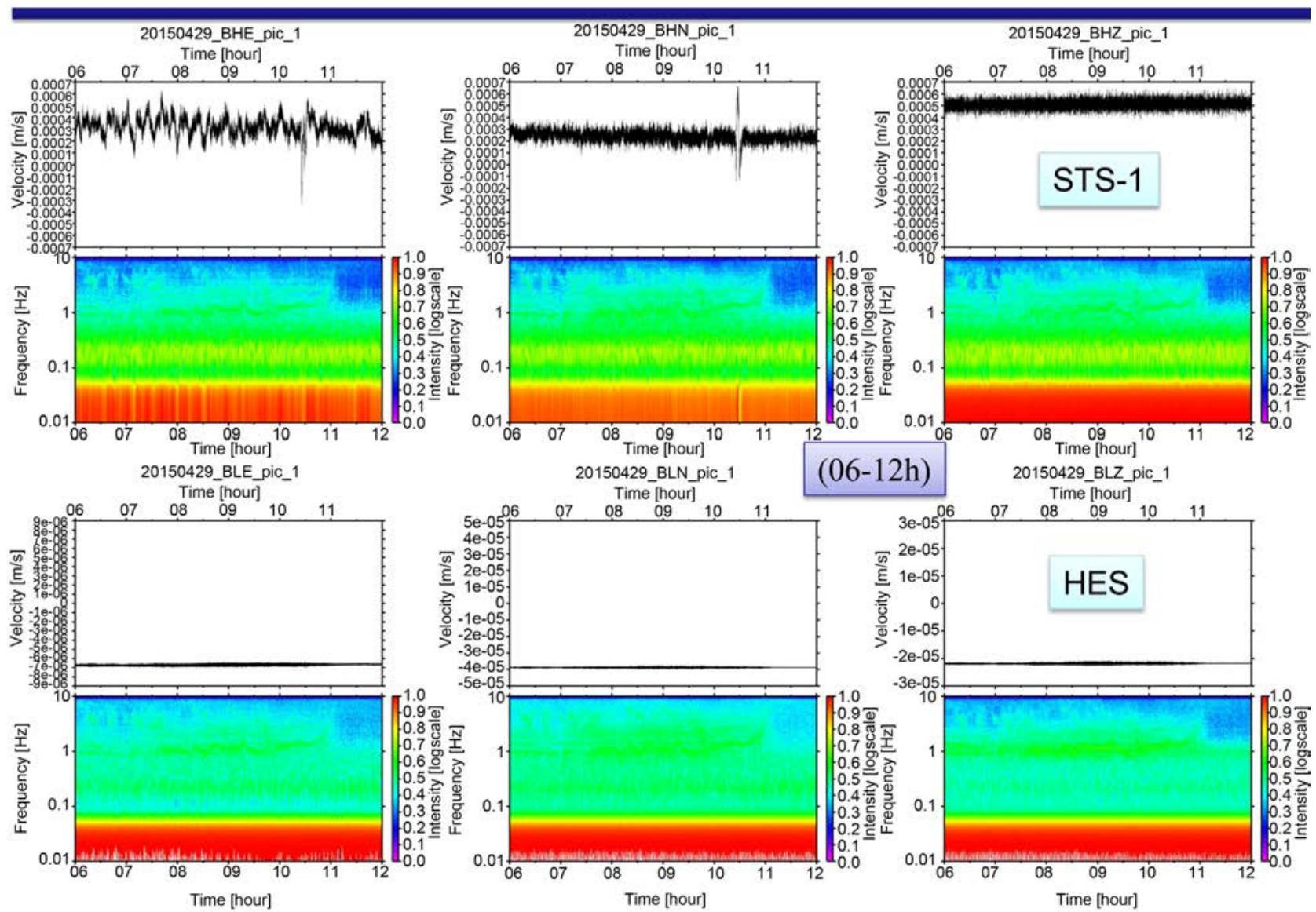

(c)

High-frequency harmonic tremor recorded at Syowa Station, 20150429 (06-12h)

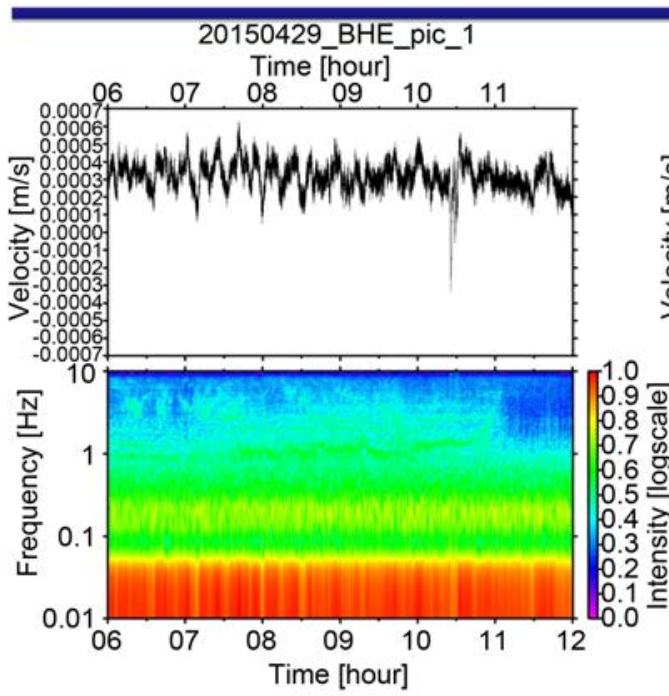

STS-1 (broadband), EW comp.

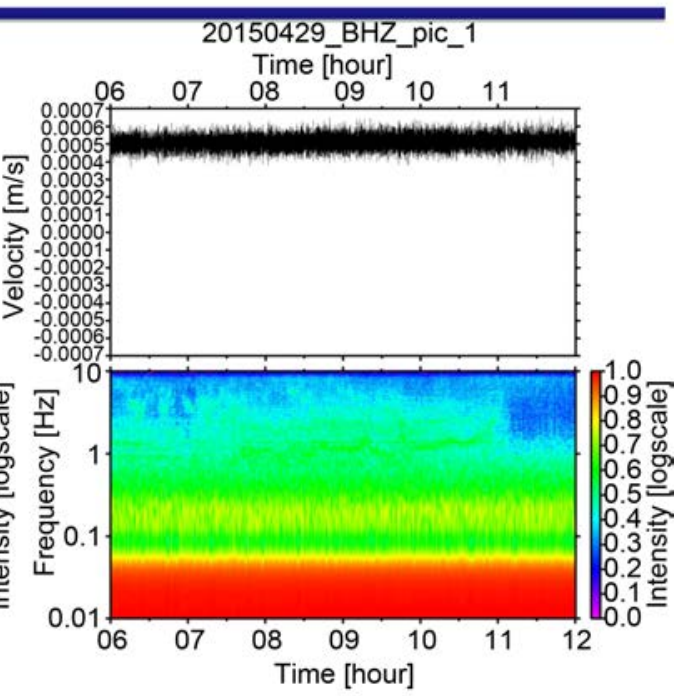

STS-1 (broadband), UD comp.

(d) 
Figure 7. (a) MODIS satellite image around LHB on 28 April, 2015. As the clouds covered over the LHB then sea-ice conditions could not be identified exactly. (b) Seismic waveforms and their power spectral densities of tremors recorded at SYO (18-24 UTC, 28 April, 2015) for both three-component short-period (HES; lower panels) and broadband seismographs (STS-1). Several serge type tremors were identified for all the components of both seismographs. (c) Seismic waveforms and their power spectral densities of tremors recorded at SYO (06-12 UTC, 29 April, 2015) for both three-component short-period (HES; lower panels) and broadband seismographs (STS-1). Long-durating non-linear harmonic tremors were recognized for all the components of both seismographs. (d) Seismic waveforms and their power spectral densities of tremors recorded at SYO (00-06 UTC, 29 April, 2015; the same event in Figure 7(c)) for horizontal and vertical components of broadband seismographs (STS-1). These harmonic tremors were presumably concidered to be generated by a kind of "collision mechanism" in cryosphere accosiated with fragments of fast sea-ice and the surrounding packed sea-ice in LHB.

Infrasound data recorded at Syowa Station, 2015 April

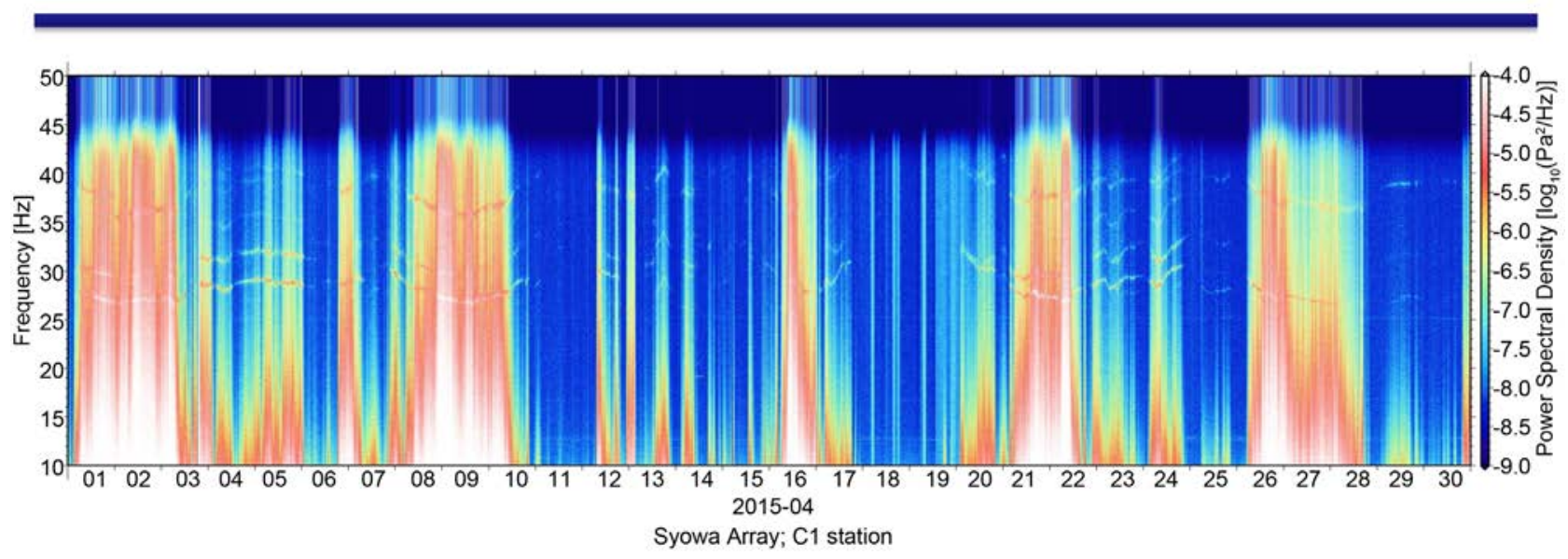

Figure 8. Power spectral densities of infrasound data recorded at SYO (one of the array sites; C1; [19]) during April 2015. High amplitudes in spectral densities were appeared at stormy days. Several non-linear harmonic overtone signals were also identified more than $25 \mathrm{~Hz}$. Details are discussed in the main text.

few minutes to few hours. These tremors occur independently at the arrivals of teleseismic phases, as well as are recorded by both types of seismographs (HES and STS-1) simultaneously. Therefore, the generating sources of the harmonic tremors are assumed to be local or regional origins. Seventeen events were previously determined by a local network deployed at LHB [13]. Majority of the events located along the coast and edge of continental shelf, where is the northern boundary of the fast sea-ice. On the basis of the evidence by this paper, several events could possibly be cryoseismic signals around LHB. As the timeline number of the tremors of the investigated period that including small and weak signal events were considered to be increased when the large storms visit LHB, giving enhancement on oceanic swells energy in Southern Indian Ocean [23]; followed by the occurrence of crashing phenomenon among the pack ices so as to illuminate the non-linear and weak tremors (as well as infrasound and hydro-acoustic signals) to some extent (for example Figure 5(b)). However, in this study, we cannot identify significant increase in a number of weak-amplitude, non-linear tremors in terms of the visits of storms in comparison with infrasound data. 
Several kinds of cryoseismic signals have been reported in several areas of the Antarctic margins. Similar harmonic tremors treating in this paper were caused by a collision of two tabular icebergs by using locally deployed seismic stations in Ross Sea [4]. It is considered that the characteristic tremor signals consist of extended episodes of stick-slip ice-quakes occurred when the ice-cliff edges of two tabular icebergs rubbed together during glancing, that was explained by the "strike-slip" iceberg collisions. Source mechanisms of such harmonic tremors might provide useful information for the study of iceberg behavior, and a possible method for remotely monitoring of the iceberg activity and evolution as well as its statistics. Additionally, non-linear type harmonic tremors associated with glacial dynamics have been found at the Whillans Ice Stream, West Antarctica [21] [24] [25] [26]. Numerical simulations of the tremor episodes at the Whillans Ice Stream were conducted that include the balance of forces acting on the fault, the evolution of rate and state dependent fault friction, and wave propagation from the fault patch to a seismometer located on the ice [26]. Simulteneous observation with geodetic measurement by GPS and tide-guage represented a strong correlation with the ocuurance time and generating procedure of these harmonic tremors. Harmonic overtones of the tremors can be explained by a repetitive source [20], suggesting existence of several inter-glacial asperities which generate the characteristic tremors. It strongly implied that the tremors in LHB might be involved in local origins, presumably cryosphere dynamics; discharge of fast-ice from the Bay, collision of icebergs and fast-ices, calving of glaciers in a vicinity of the stations.

The seismic tremors in terms of cryosphere dynamics, as demonstrated in this paper, are likely to be associated with time-space variations in surface environments, thus it is expected that continuous monitoring of their time-space variation provides indirect evidence of climate change in the Antarctic. There are still a lot to be learned about physical mechanisms of the occurrence of cryoseismic tremors and interaction mechanism between cryosphere and the solid earth in polar region. Continuous observation by a sufficient number of high quality seismic stations, in addition to theoretical modeling works, could make advance in this new branch of inter-disciplinary science of "Cryoseismology". Given the high cost and technical difficulties of continuous observation in polar region, such the great efforts require successive international collaboration beyond the International Polar Year.

\section{Conclusions}

In summary, characteristics and statistics of seismic tremors occurring during one month of April 2015 were investigated by using seismographs deployed at Syowa Station (SYO), in LHB, East Antarctica. To examine a relationship between surface environmental changes in particular cryosphere dynamics, the MODIS satellite images were utilized for comparison with the seismic waveforms for each tremor events. Since a large volume of sea-ice was discharged during the 
April, together with several large icebergs passed through from the west to the east at northern edge of LHB, it was expected to reveal a relationship between occurrence of the tremors and surrunding environment.

During the month of April 2015, a total number of 49 tremors including short duration ice shocks were identified in both short-period and broadband seismographs. Majority of the events $(\mathrm{N}=39)$ had their duration times more than 15 minutes, which were the experience definition for dividing tremors and ice shocks at SYO. Several kinds of cryosphere source origins for detected seismic tremors were classified (collision, calving, crevassing, crashing, etc.) by the comparison with MODIS satellite images; "crevassing events" along the large cracks inside the fast sea-ice (04 April), "discahrge events" of fast sea-ice in LHB (07 April), "collision events" between the iceberg and the edge of fast sea-ice (14 April), "crashing movement" between fragmentation of fast sea-ice and packed sea-ice (18 April), and the other origins. In particular, strong amplitude tremors with harmonic overtones were assumed to be occurring independently from weather condition, since these overtone tremors were recognized during less stormy days on the basis of infrasound data at SYO.

\section{Acknowledgements}

The authors would like to express their sincere appreciation to many colleagues who dedicatedly supported to operate the seismic observation at Syowa Station and around LHB, including members of the Japanese Antarctic Research Expeditions (JARE). This work was supported by JSPS KAKENHI Grant Number 26241010 (P. I. by Dr. Masaki Kanao). Finally, the author would like to express thankfulness to the reviewers for giving useful comments, as well as the editorial office of the journal for publishing this paper.

\section{References}

[1] Wilson, T. and Bell, R. (2011) Earth Structure and Geodynamics at the Poles. Understanding Earth's Polar Challenges. International Polar Year 2007-2008, 273-292.

[2] Bohnenstiehl, D., Dziak, R.P., Parlk, M. and Matsumoto, H. (2005) Seismicity of the Polar Seas: The Potential for Hydroacoustic Monitoring of Tectonic and Volcanic Processes. The 12th Seoul International Symposium on Polar Science, Ansan, 17-19 May 2005, 11-14.

[3] Eckstaller, A., Müller, C., Ceranna, L. and Hartmann, G. (2007) The Geophysics Observatory at Neumayer Stations (GvN and NM-II) Antarctica. Polarforshung, 76, 3-24.

[4] MacAyeal, D.R., Okal, E.A., Aster, R.C. and Bassis, J.N. (2008) Seismic and Hydroacoustic Tremor Generated by Colliding Icebergs. Journal of Geophysical Research, 113, F03011. https://doi.org/10.1029/2008JF001005

[5] MacAyeal, D.R., Okal, E.A., Aster, R.C. and Bassis, J.N. (2009) Seismic Observations of Glaciogenic Ocean Waves on Icebergs and Ice Shelves. Journal of Glaciology, 55, 193-206. https://doi.org/10.3189/002214309788608679

[6] Dziak, R.P., Parlk, M., Lee, W.S., Matsumoto, H., Bohnenstiehl, D.R. and Haxel, J.H. (2009) Tectono-Magmatic Activity and Ice Dynamics in the Bransfield Strait 
Back-Arc Basin, Antarctica. The 16th International Symposium on Polar Sciences, Incheon, 10-12 June 2009, 59-68.

[7] Peng, Z., Walter, J.I., Aster, R.C., Nyblade, A., Wiens, D.A. and Anandakrishnan, S. (2014) Antarctic Icequakes Triggered by the 2010 Maule Earthquake in Chile. $\mathrm{Na}$ ture Geoscience, 7, 677-681. https://doi.org/10.1038/ngeo2212

[8] Hammer, C., Ohrnberger, M. and Schlindwein, V. (2015) Pattern of Cryospheric Seismic Events Observed at Ekstrom Ice Shelf, Antarctica. Geophysical Research Letters, 42, 3936-3943. https://doi.org/10.1002/2015GL064029

[9] Ekström, G., Nettles, M. and Tsai, V.C. (2006) Seasonality and Increasing Frequency of Greenland Glacial Earthquakes. Science, 311, 1756-1758. https://doi.org/10.1126/science.1122112

[10] Nettles, M. and Ekström, G. (2010) Glacial Earthquakes in Greenland and Antarctica. The Annual Review of Earth and Planetary Sciences, 38, 467-491. https://doi.org/10.1146/annurev-earth-040809-152414

[11] Clinton, J.F., Nettles, M., Walter, F., Anderson, K., Dahl-Jensen, T., Giardini, D., Govoni, A., Hanka, W., Lasocki, S., Lee, W.S., McCormack, D., Mykkelveit, S., Stutzmann, E. and Tsuboi, S. (2014) Real-Time Geophysical Data Enhance Earth System Monitoring in Greenland. Eos, Transactions, American Geophysical Union, 95, 13-24. https://doi.org/10.1002/2014EO020001

[12] Podolskiy, E.A., Sugiyama, S., Funk, M., Walter, F., Genco, R., Tsutaki, S., Minowa, M. and Ripepe, M. (2016) Tide-Modulated Ice Flow Variations Drive Seismicity near the Calving Front of Bowdoin Glacier, Greenland. Geophysical Research Letters, 43, 2036-2044. https://doi.org/10.1002/2016GL067743

[13] Kanao, M. and Kaminuma, K. (2006) Seismic Activity Associated with Surface Environmental Changes of the Earth System, East Antarctica. In: Futterer, D.K., Damaske, D., Kleinschmidt, G., Miller, H. and Tessensohn, F., Eds., Antarctica: Contributions to Global Earth Sciences, Springer, Berlin, 361-368. https://doi.org/10.1007/3-540-32934-X_45

[14] Kanao, M., Maggi, A., Ishihara, Y., Yamamoto, M.-Y., Nawa, K., Yamada, A., Wilson, T., Himeno, T., Toyokuni, G., Tsuboi, S., Tono, Y. and Anderson, K. (2012b) Interaction of Seismic Waves between Atmosphere-Ocean-Cryosphere and Geosphere in Polar Region. In: Kanao, M., Takenaka, H., Murai, Y., Matsushima, J. and Toyokuni, G., Eds., Seismic Waves-Research and Analysis, InTech, Rijeka, Croatia, 1-20. https://doi.org/10.5772/23410

[15] Kanao, M. (2017) Characterictics of Seismic Wave Propagation of Harmonic Tremors Observed at the Margin in the Lützow-Holm Bay, East Antarctica. Earthquakes-Tectonics, Hazard and Risk Mitigation, InTech, Rijeka, Croatia, Chapter 4, 71-85.

[16] Kanao, M. (2017) Statistics of Seismic Tremors with Harmonic Overtones Recorded at Syowa Station, Antarctica: October 2014-March 2015. International Journal of Geosciences, 8, 811-820. https://doi.org/10.4236/ijg.2017.86046

[17] Kanao, M. (2010) Detection Capability of Teleseismic Events Recorded at Syowa Station, Antarctica-1987 2007. Antarctic Record, 54, 11-31.

[18] Kanao, M., Storchak, D. and Dando, B. (2012) Evaluation of Long-Period Detectability of Teleseismic Events at Syowa Station, Antarctica. International Journal of Geosciences, 3, 809-821. https://doi.org/10.4236/ijg.2012.324082

[19] Murayama, T., Kanao, M., Yamamoto, M.-Y., Ishihara, Y., Matsushima, T., Kakinami, Y., Okada, K., Miyamachi, H., Nakamoto, M., Takeuchi, Y. and Toda, S. (2017) Time-Space Variations of Insrasound Sources Involving Environmental Dy- 
namics around the Lützow-Holm Bay, East Antarctica. Polar Science. [Under Review]

[20] Powell, T.W. and Neuberg, J. (2003) Time Dependent Features in Tremor Spectra. Journal of Volcanology and Geothermal Research, 128, 177-185. https://doi.org/10.1016/S0377-0273(03)00253-1

[21] Winberry, J.P., Anandakrishnan, A., Wiens, D.A. and Alley, R.B. (2013) Nucleation and Seismic Tremor Associated with the Glacial Earthquakes of Whillans Ice Stream, Antarctica. Geophysical Research Letters, 40, 312-315. https://doi.org/10.1002/grl.50130

[22] Murayama, T., Kanao, M., Yamamoto, M.-Y., Ishihara, Y., Matshushima, T. and Kakinami, Y. (2015) Infrasound Array Observations in the Lützow-Holm Bay Region, East Antarctica. Polar Science, 9, 35-50. https://doi.org/10.1016/j.polar.2014.07.005

[23] Stutzmann, E., Schimmel, M., Patau, G. and Maggi, A. (2009) Global Climate Imprint on Seismic Noise. Geochemistry, Geophysics, Geosystems, 10, Q11004. https://doi.org/10.1029/2009GC002619

[24] Winberry, J.P., Anandakrishnan, A., Wiens, D.A., Alley, R.B. and Christianson, K. (2011) Dynamics of Stick-Slip Motion, Whillans Ice Stream, Antarctica. Earth and Planetary Science Letters, 305, 283-289. https://doi.org/10.1016/j.epsl.2011.02.052

[25] Pratt, M.J., Winberry, J.P., Wiens, D.A., Anandakrishnan, S. and Alley, R.B. (2014) Seismic and Geodetic Evidence for Grounding-Line Control of Whillans Ice Stream Stick-Slip Events. Journal of Geophysical Research Earth Surface, 119, 333-348. https://doi.org/10.1002/2013JF002842

[26] Lipovsky, B.P. and Dunham, E.M. (2016) Tremor during Ice-Stream Stick Slip. The Cryosphere, 10, 385-399. https://doi.org/10.5194/tc-10-385-2016

Submit or recommend next manuscript to SCIRP and we will provide best service for you:

Accepting pre-submission inquiries through Email, Facebook, LinkedIn, Twitter, etc. A wide selection of journals (inclusive of 9 subjects, more than 200 journals)

Providing 24-hour high-quality service

User-friendly online submission system

Fair and swift peer-review system

Efficient typesetting and proofreading procedure

Display of the result of downloads and visits, as well as the number of cited articles

Maximum dissemination of your research work

Submit your manuscript at: http://papersubmission.scirp.org/

Or contact ijg@scirp.org 